\title{
Governança corporativa voltada à Produção Mais Limpa: influência dos stakeholders
}

\section{Corporate governance focused on cleaner production: the influence of stakeholders}

\author{
Geraldo Cardoso de Oliveira Neto ${ }^{1,2}$ \\ Moacir Godinho Filho ${ }^{2}$ \\ Oduvaldo Vendrametto ${ }^{3}$ \\ Gilberto Miller Devós Ganga² \\ Irenilza Alencar Naas ${ }^{3}$
}

\begin{abstract}
Resumo: Este estudo visa avaliar as influências dos stakeholders na determinação de uma Governança Corporativa voltada à Produção Mais Limpa $(\mathrm{P}+\mathrm{L})$. Primeiramente identificaram-se na literatura três constructos que exercem influência sobre a governança da empresa para a implementação da $\mathrm{P}+\mathrm{L}$, que são: política pública, agentes econômicos e sociedade. Depois disso, realizou-se um survey em empresas associadas ao Instituto Ethos. Para a avaliação estatística, utilizou-se a análise de componentes principais para dados categóricos ou nominais. Os resultados apontaram algumas tendências em termos de influências dos stakeholders, direcionando a mudanças de princípios da governança corporativa, que conseguinte impulsionam mudanças endógenas e incrementais no sistema de produção para a implantação da $\mathrm{P}+\mathrm{L}$. A política pública tende a taxar emissões de carbono das empresas e promover financiamento a juros baixos para investimento em tecnologias limpas e controle da produção no sistema de produção, o agente econômico tende a se conscientizar e obedecer a leis ambientais que levam à implantação de $\mathrm{P}+\mathrm{L}$, e a sociedade tende a comprar produtos ecológicos, além de denunciar práticas enganosas das empresas.
\end{abstract}

Palavras-chave: Produção Mais Limpa. Governança corporativa. Política pública. Economia solidária. Responsabilidade social.

\begin{abstract}
This study aims to evaluate the influence of stakeholders in determining a Corporate Governance focused on Cleaner Production (CP). First, three constructs that influence the governance of enterprises to implement CP were identified in the literature: public policy, economic agents, and society. After that, a survey was carried out in companies associated with the Ethos Institute. Regarding statistical analysis, principal components analysis was conducted for categorical or nominal data. The results showed some trends in terms of stakeholders' influences, directing changes in the principles of corporate governance, which consequently boost endogenous and incremental changes in the production system for the deployment of CP. Public policy tends to tax carbon emissions from companies and promote low-interest financing for investment in clean technologies and production control in the production system; the economic agent tends to become aware of and comply with environmental laws that lead to implantation of CP; and society tends to buy green products and report deceptive business practices.
\end{abstract}

Keywords: Cleaner production. Corporate governance. Public policy. Solidarity economy. Socio responsibility.

\section{Introdução}

Até a década de 1990, as empresas tinham como foco central estratégico a maximização do retorno financeiro aos seus acionistas. Já nas décadas seguintes, por influência de um ambiente de concorrência global e pressões por adequações legais às questões ambientais e sociais, estas organizações passaram a focar suas atenções à incorporação destas temáticas em seus processos de negócios (ELKINGTON, 1997; GIBSON, 2012). Desta forma, o processo produtivo nas organizações, por exigência de mercado e das normas e leis atuais, passou a adotar, além da eficiência econômica, a responsabilidade social e ambiental (ABREU; RADOS; FIGUEIREDO JUNIOR, 2004; BARBIERI et al., 2010), tornando-as

\footnotetext{
${ }^{1}$ Programa de Mestrado em Engenharia da Produção, Universidade Nove de Julho - UNINOVE, Avenida Francisco Matarazzo, 612, CEP 01156-050, Barra Funda, SP, Brasil, e-mail: geraldo.prod@ig.com.br

2 Programa de Mestrado e Doutorado em Engenharia da Produção, Universidade Federal de São Carlos - UFSCar, Rodovia Washington Luís, km 235 - SP 310, Jardim Guanabara, CEP 13565-905, São Carlos, SP, Brasil

${ }^{3}$ Programa de Mestrado e Doutorado em Engenharia da Produção, Universidade Paulista - UNIP, Rua Bacelar, 1212, Vila Clementino, CEP 04026-002, São Paulo, SP, Brasil
}

Recebido em Out. 22, 2013 — Aceito em Maio 6, 2014

Suporte financeiro: Nenhum. 
atributo estratégico (LEE, 2012) para manter a competitividade (BRITO; BERNARDI, 2010).

Dentre as atividades sustentáveis que compõem o conceito da Produção Mais Limpa $(\mathrm{P}+\mathrm{L})$ estão a redução no uso de recursos, as melhorias na ecoeficiência e redução de resíduos de embalagens e industriais na fonte, visando melhorar a proteção do meio ambiente, além da redução de riscos para os organismos vivos (UNITED..., 1989; GLAVIC; LUKMAN, 2007). Um aspecto para a efetiva consolidação da sustentabilidade na cadeia de valor intraorganizacional e interfirmas é a gestão do relacionamento com os stakeholders (FREEMAN; REED, 1983; LYRA; GOMES; JACOVINE, 2009; LEE, 2012). Do ponto de vista da estratégia empresarial, os stakeholders visam estabelecer canal de comunicação e compreender as suas necessidades para as decisões de marketing e operações.

A influência do governo e da sociedade estimulam as empresas a melhorar o desempenho ambiental na fabricação de bens e serviços (CHRISTMANN, 2004; KOLK; PINKSE, 2007), impulsionando a governança corporativa a incorporar a P+L (KING; LENOX, 2000), além de melhorar o desempenho financeiro (JO; HARJOTO, 2012).

Considerando que no Brasil este tema é pouco pesquisado, este trabalho objetiva avaliar as principais influências dos stakeholders na governança corporativa voltada à $\mathrm{P}+\mathrm{L}$ de empresas brasileiras, testando a hipótese central de que os stakeholders influenciam positivamente a adoção de uma governança corporativa voltada à $\mathrm{P}+\mathrm{L}$.

\section{Fundamentação teórica das influências exógenas na concepção da Produção Mais Limpa}

As influências exógenas analisadas neste trabalho são assim discriminadas:

(i) influências da política pública: para coordenar ações, efetivar direitos e intervir na realidade social, criando políticas públicas para o desenvolvimento sustentável (YARIME et al., 2012; CARVALHO et al., 2012). O governo tem concedido empréstimos a juros baixos e redução de tarifas fiscais de apoio à fabricação de produtos sustentáveis, como meio de regulação ambiental (GARCÍA; MENDOZA, 2010; HALEY; SCHULER, 2011). Entretanto, nota-se a falta da abordagem educativa (ELLERBROCK; REGN, 2004).

(ii) influências dos agentes econômicos: são os investidores, proprietários que visam ao crescimento econômico, mas tendem a adotar princípios do desenvolvimento sustentável
(RIVERO, 2002; VEIGA, 2005), por meio da implementação da $\mathrm{P}+\mathrm{L}$ para gerar vantagens econômicas e ambientais (BRATTEBO, 2005; BURRITT; SAKA, 2006; GIANNETTI; ALMEIDA, 2006; KNIGHT; JENKINS, 2009).

(iii) influências da sociedade: impulsionam ações ambientais sobre as empresas para implementação da P+L (CHITAKORNKIJSIL, 2012), direcionando-as ao comportamento de compra ecológica (PICKETT-BAKER; OZAKI, 2008). Porém, o valor agregado do produto ecológico dificulta a procura, principalmente porque somente com o aumento da demanda será possível obter preços similares (HEAL, 2000). O Quadro 1 apresenta 22 influências da política pública exercidas sobre as organizações para a implantação da P+L. Com isso, entende-se que a política pública impulsiona as organizações de maneira educativa e/ou por meio de repressão taxativa a adesão a práticas ambientais no sistema de produção.

Quanto aos agentes econômicos (ECO) (Quadro 2), entende-se que eles exercem influência para a implantação da $\mathrm{P}+\mathrm{L}$, principalmente por ter a possibilidade de conquistar ganhos econômicos e ambientais em detrimento dessa implantação.

Já, com relação àquelas influências relativas à sociedade (SOC) (Quadro 3), que denotam mudança de comportamento em relação à compra verde, impulsionam as empresas a produzirem produtos ecológicos.

Considerando-se que a governança corporativa tende a funcionar como uma mola propulsora (Figura 1), que capta as influências exógenas da política pública, agentes econômicos e sociedade e direciona os esforços para a perspectiva de inclusão do desenvolvimento sustentável na declaração formal da alta administração, impulsionando mudanças para uma P+L. Vários autores e comissões governamentais consideram que a governança corporativa recebe influências dos stakeholders e promove mudanças endógenas, que incluem a implantação da $\mathrm{P}+\mathrm{L}$ (O'ROURKE, 2003; MIRVIS; GOOGINS, 2006; ZHANG et al., 2008; SHANGHAI..., 2009; ZENG et al., 2010; MAON; LINDGREEN; VALÉRIE SWAEN, 2010; NAVICKAS; KONTAUTIENE, 2011; ORTAS; BURRITT; MONEVA, 2013).

As empresas na busca de imagem de empresa socialmente correta direcionam esforços para a implantação de governança corporativa ambiental e social, que precisa investir em práticas ambientais na produção de bens (O'ROURKE, 2003), nota-se que as empresas precisam estar atentas às influências externas dos stakeholders e gerar mudanças nos processos de produção (MIRVIS; GOOGINS, 
Quadro 1. Influências exercidas pela política pública para a implementação da Produção Mais Limpa.

\begin{tabular}{|c|c|}
\hline Influências & Conceito \\
\hline $\begin{array}{l}\text { PP1) Comunicação para Sensibilizar as } \\
\text { Indústrias visando à Conscientização } \\
\text { como Princípio da Precaução }\end{array}$ & $\begin{array}{l}\text { As organizações tendem a estabelecer a comunicação com as indústrias } \\
\text { como princípio de precaução (VON SCHOMBERG, 2012; RICHIE; } \\
\text { OPPENHEIMER; CLARK, 2012), para evitar desastres (PERRINGS, } \\
\text { 1991). }\end{array}$ \\
\hline $\begin{array}{l}\text { PP2) Estímulo à Reforma Tributária } \\
\text { Ecológica, com Subsídios e Redução de } \\
\text { Impostos }\end{array}$ & $\begin{array}{l}\text { Visa taxar atividades intensivas de poluição das indústrias e emissões } \\
\text { de carbono e reduzir os impostos sobre o trabalho (DALY, 2005; } \\
\text { WANGLER, 2012; LIPSCY, 2012). }\end{array}$ \\
\hline $\begin{array}{l}\text { PP3) Combate à poluição, Exigências de } \\
\text { Implementação de Tecnologias Limpas }\end{array}$ & $\begin{array}{l}\text { A política pública tende a criar leis e indicadores para redução da } \\
\text { poluição, visando ao uso de tecnologias limpas (WANGLER, 2012). }\end{array}$ \\
\hline $\begin{array}{l}\text { PP4) Intervenção Jurisdicional rápida e } \\
\text { eficiente para Impedir que novos Danos } \\
\text { Ambientais venham a ocorre. }\end{array}$ & $\begin{array}{l}\text { A arbitragem deve garantir a aptidão para o alcance de proteção } \\
\text { jurisdicional efetiva do direito fundamental ao meio ambiente de } \\
\text { maneira rápida e eficiente (LIMA, 2010; HAUBRICH, 2004). }\end{array}$ \\
\hline $\begin{array}{l}\text { PP5) Penalização e cobrança de } \\
\text { Indenização sobre a Extração de }\end{array}$ & $\begin{array}{l}\text { É importante a cobrança de indenização de extração de recursos } \\
\text { (HAUBRICH, 2004). }\end{array}$ \\
\hline
\end{tabular}

Recursos Naturais

PP6) Transparência e livre acesso

à Informação sobre aspectos

Socioambientais das Empresas

Exigir o acesso de informações socioambientais das empresas e

stakeholders, podendo ocorrer recusa de transparência das organizações (VACCARO; ECHEVERRI, 2010).

PP7) Assumir que a Crise Ambiental

A crise ambiental deve ser informada pela política pública

Fragiliza a Natureza e ameaça a

Humanidade

(MCCHESNEY, 2012). No Brasil, com base no IBAMA o governo deve considerar o meio ambiente como um patrimônio público.

PP8) Divulgar Informações que permitirão valorizar e Conservar o

Meio Ambiente, tais como zoneamento

ecológico, gestão de bacias hidrográficas

e destinação do lixo

A política pública deve informar sobre a conservação do meio ambiente (FARLEY, 2010). No Brasil: (i) Decreto no 4297/02 que regulamenta

a lei no 6938/81 para o zoneamento ecológico; (ii) Lei no 9433/97,

que institui a gestão de bacias hidrográficas; e, (iii) Gestão do lixo doméstico e industrial (SEIFFERT, 2010).

PP9) Estabelecimento de Legislação para Controle ambiental junto a um Tribunal Arbitral

PP10) Comunicação de Riscos e restrições de uso de Substâncias Nocivas à Saúde

Importante estabelecer controle ambiental para regulação (BACKER, 2008), submetida pelo juízo arbitral para evitar agressões ao meio ambiente e penalização em caso de infração (LIMA, 2010).

O papel do Estado permite o conhecimento sobre os riscos e restrições ao uso de substâncias nocivas à saúde (GORDON, 2002; MCBRIDE et al., 2012).

PP11) Análises Ambientais nas Empresas para Disseminar a Informação

Monitoração do desempenho ambiental organizacional por meio de fiscalização da instalação operacional para tornar as informações públicas (DÉNIZ-DÉNIZ; GARCIA-FALCON, 2002).

PP12) Estabelecimento de Taxas progressivas para atividades intensivas em Emissões de Carbono

Implantar taxação para emissões de carbono (CIOCIRLAN; YANDLE, 2003; QU; QU, 2011; SCANDIZZO; KNUDSEN, 2012), para compensação financeira, diretas (vendas de certificados de emissão) ou indiretas (redução de impostos a pagar) (LUSTOSA, 2010).

PP13) Cobrança pelo Despejo de Efluentes Poluidores

Implantar taxação para despejo de efluentes poluidores (LYON; JOHN, 2003). No Brasil, lei n 20 menciona que a política pública tende a cobrar da indústria por $\mathrm{m}^{3} \mathrm{o}$ despejo de efluentes contaminantes para repassar a receita no tratamento da água para abastecimento (SEIFFERT, 2010).

PP14) Avaliação dos Equipamentos e Máquinas Tecnológicas na Produção

Estabelecer normas, controles, padrões nos processos industriais, exigindo a implementação de tecnologia limpa e/ou equipamentos para redução da poluição (LUSTOSA, 2010; WANGLER, 2012).

PP15) Utilização de Controle sobre: recursos hídricos; sistema de licenciamento ambiental; código florestal; política nacional do meio ambiente; resíduos sólidos; e gases do efeito estufa
Importante estabelecer controle ambiental para regulação (BACKER, 2008; QU; QU, 2011) dos: (i) recursos hídricos, exigindo licença prévia, licença de instalação e a licença de operação, fundamentada na resolução do CONAMA n ${ }^{\circ}$ 237/1997 (SEIFFERT, 2010); (ii) o código da floresta, no qual a agenda 21 define na seção II o combate ao desflorestamento; (iii) a compreensão e discernimento sobre o meio ambiente (RIVELLI, 2005); (iv) a destinação correta dos resíduos sólidos (POLÍTICA..., 2010); e, (v) o controle das emissões de dióxido de carbono (SEIFFERT, 2010). 
Quadro 1. Continuação...

\begin{tabular}{|l|l|}
\hline \multicolumn{1}{|c|}{ Influências } & \multicolumn{1}{c|}{ Conceito } \\
\hline PP16) Promover Fóruns de Discussões & $\begin{array}{l}\text { Instrumentos de negociação e mediação que visam discutir a } \\
\text { sustentabilidade (CONRAD; COSTELLO, 2002; SINGH, 2012). }\end{array}$ \\
\hline $\begin{array}{l}\text { PP17) Estimular e Conscientizar sobre a } \\
\text { Autorregulação Ambiental }\end{array}$ & $\begin{array}{l}\text { A política pública deve conscientizar os envolvidos sobre educação } \\
\text { ambiental (YARIME et al., 2012; CARVALHO et al., 2012). }\end{array}$ \\
\hline $\begin{array}{l}\text { PP18) Controle Ambiental da Gestão } \\
\text { Pública com Transparência }\end{array}$ & $\begin{array}{l}\text { A política pública precisa ser mais transparente quanto à } \\
\text { sustentabilidade (DÉNIZ-DÉNIZ; GARCIA-FALCON, 2002; } \\
\text { VACCARO; ECHEVERRI, 2010) }\end{array}$ \\
\hline $\begin{array}{l}\text { PP19) Debates com Informativos das } \\
\text { Políticas Públicas para a Sociedade }\end{array}$ & $\begin{array}{l}\text { Estabelecer debates informativos sobre sustentabilidade para a } \\
\text { sociedade (CONRAD; COSTELLO, 2002; SINGH, 2012). }\end{array}$ \\
\hline $\begin{array}{l}\text { PP20) Avaliações sobre Reuniões de } \\
\text { Bairro para tratar de assuntos sobre a } \\
\text { Sustentabilidade }\end{array}$ & $\begin{array}{l}\text { Visa participar e avaliar as reuniões de bairro em prol da } \\
\text { sustentabilidade com o objetivo de buscar comprometimento da } \\
\text { sociedade (CONRAD; COSTELLO, 2002; SIMÃO et al., 2010; } \\
\text { SINGH, 2012). }\end{array}$ \\
\hline $\begin{array}{l}\text { PP21) Iniciativas de Separação de Lixos } \\
\text { na Coleta Seletiva }\end{array}$ & $\begin{array}{l}\text { É necessário a política pública incentivar a separação de lixo (RUMPALA, } \\
\text { 2011). No Brasil, os indicadores de sustentabilidade do IBGE } \\
\text { (INSTITUTO..., 2004) visam ao acesso ao serviço de coleta de lixo. }\end{array}$ \\
\hline $\begin{array}{l}\text { PP22) O Aumento da Venda de Produtos } \\
\text { Ecológicos }\end{array}$ & $\begin{array}{l}\text { É importante a política pública avaliar se a sociedade está comprando } \\
\text { produtos ecológicos (LEE, 2006). }\end{array}$ \\
\hline
\end{tabular}

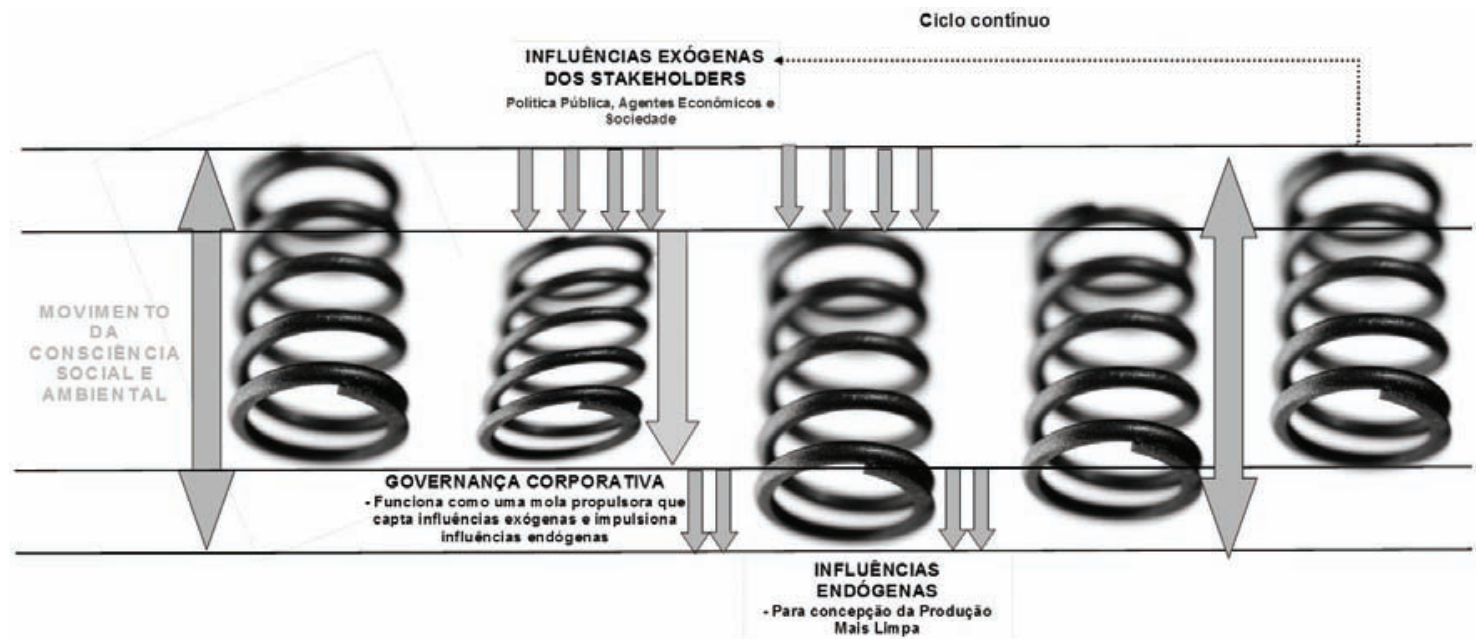

Figura 1. Mola propulsora para concepção da $\mathrm{P}+\mathrm{L}$.

2006). As pressões externas do governo, acionistas e sociedade estão alterando as governanças das empresas em direção à implantação da estratégia de $\mathrm{P}+\mathrm{L}$, visando aos padrões de consumo sustentável (ZHANG et al., 2008). O relacionamento com os stakeholders constitui um processo de gestão de risco realizado pela governança corporativa com o objetivo de conformidade e de manter sua licença para operar, por isso progressivamente trabalha para desenvolver uma gestão eficiente nos processos de produção para alcançar legitimidade, resultando em práticas de $\mathrm{P}+\mathrm{L}$ (MAON; LINDGREEN; VALÉRIE SWAEN, 2010).

Por exemplo, o governo de Xangai, o centro da economia da China, tem feito grandes esforços para acelerar a reestruturação do sistema e melhorar o layout da indústria de transformação. Em 2003, o governo de Xangai emitiu "Orientação para o desenvolvimento da indústria de fabricação", que agrupou em três categorias: (i) aqueles incentivados a desenvolver; (ii) aqueles proibidos de desenvolver; e (iii) aqueles restritos a desenvolver. Os setores industriais que prejudicam o meio ambiente foram proibidos de funcionamento. Outros setores são obrigados a implantar políticas de $\mathrm{P}+\mathrm{L}$ para mitigar poluição (SHANGHAI..., 2009). O mesmo resultado foi evidenciado no mesmo país, porém os autores sugeriram para pesquisas futuras, a identificação de quais são os principais influenciadores (a citar: sociedade, governo e acionistas) (ZENG et al., 2010). Na Lituânia, foi desenvolvida uma projeção pelo governo em reunião com as empresas, as quais terão que implantar práticas de $\mathrm{P}+\mathrm{L}$ até 2020 (NAVICKAS; KONTAUTIENE, 2011). 
Quadro 2. As influências exercidas pelos agentes econômicos para a implementação da Produção Mais Limpa.

\begin{tabular}{|c|c|}
\hline Influências & Conceito \\
\hline $\begin{array}{l}\text { ECO1)O Custo Ambiental é } \\
\text { entendido como Investimento } \\
\text { nas gerações futuras }\end{array}$ & $\begin{array}{l}\text { É imprescindível gerar custo ambiental para o desenvolvimento sustentável } \\
\text { (GREPPERUD, 2007; ZAHARIA; ZAHARIA, 2012). }\end{array}$ \\
\hline $\begin{array}{l}\text { ECO2) A Criação de Valor } \\
\text { para os Acionistas no que } \\
\text { tange à Marca e à Reputação }\end{array}$ & $\begin{array}{l}\text { A produção de produtos verdes gera valor para os acionistas em marca e reputação } \\
\text { (ZAMAGNI, 2009). }\end{array}$ \\
\hline $\begin{array}{l}\text { ECO3) O conceito de } \\
\text { Ecoeficiência pode trazer } \\
\text { Vantagens Econômicas e } \\
\text { Ambientais }\end{array}$ & $\begin{array}{l}\text { A ecoeficiência visa minimizar impactos ambientais de maneira preventiva. Reduz } \\
\text { o uso de matérias-primas, energia e materiais tóxicos (KNIGHT; JENKINS, } \\
\text { 2009). Visa produzir mais com menos, uso reciclagem e uso de recursos de fontes } \\
\text { renováveis, gerando vantagens econômicas e ambientais (GIANNETTI; ALMEIDA, } \\
\text { 2006). }\end{array}$ \\
\hline $\begin{array}{l}\text { ECO4) A necessidade de } \\
\text { Investimento econômico em } \\
\text { Tecnologias Limpas }\end{array}$ & É necessário investir em tecnologia limpa (ZAHARIA; ZAHARIA, 2012). \\
\hline $\begin{array}{l}\text { ECO5) A Facilidade de } \\
\text { Financiamento de recursos } \\
\text { financeiros para o Investimento }\end{array}$ & $\begin{array}{l}\text { Os subsídios atuam como incentivos para investimento e financiamentos } \\
\text { (BHATTACHARYYA, 2007), com o objetivo de estimular a redução da poluição no } \\
\text { sistema produtivo (MAIMON, 1996). }\end{array}$ \\
\hline $\begin{array}{l}\text { ECO6) Elevação da Taxa de } \\
\text { Juros de Extração no que } \\
\text { tange aos Recursos Escassos }\end{array}$ & $\begin{array}{l}\text { A elevação da taxa de juros de recursos escassos tende a mudar o comportamento } \\
\text { de compra dos empresários, buscando materiais de fontes renováveis (ZÁRATE- } \\
\text { MARCO; VALLÉS-GIMÉNEZ, 2012). }\end{array}$ \\
\hline $\begin{array}{l}\text { ECO7) A facilidade de } \\
\text { usabilidade de Mecanismos } \\
\text { de Desenvolvimento Limpo } \\
\text { (MDL) }\end{array}$ & $\begin{array}{l}\text { O projeto MDL foi iniciado na sexta conferência das partes do Protocolo de Kyoto, } \\
\text { visando à redução de emissões (GOMEZ-BAGGETHUN; RUIZ-PEREZ, 2011), } \\
\text { contribui com o desenvolvimento sustentável local, visando: transferência de } \\
\text { tecnologia e financiamento de baixo custo pelo governo para monitorar as metas de } \\
\text { mitigação de gás carbônico e consumo de energia (LI; COLOMBIER, 2011). }\end{array}$ \\
\hline $\begin{array}{l}\text { ECO8) Tornar a Economia } \\
\text { global mais Inclusiva } \\
\text { visando ao Desenvolvimento } \\
\text { Sustentável }\end{array}$ & $\begin{array}{l}\text { Os agentes econômicos precisam se comprometer com o desenvolvimento } \\
\text { sustentável, considerando a redução dos impactos ambientais causados pelas } \\
\text { atividades produtivas, possibilitando melhorar a competitividade no mercado } \\
\text { (IBRAHIM, 2012; TENCATI; ZSOLNAI, 2012). }\end{array}$ \\
\hline $\begin{array}{l}\text { ECO9) O Capital e os Recursos } \\
\text { Naturais são essencialmente } \\
\text { Complementares }\end{array}$ & $\begin{array}{l}\text { O capitalismo liberal busca o uso de recursos naturais renováveis, visando reduzir a } \\
\text { poluição e conquistar novos mercados (FREEMAN, 2011). }\end{array}$ \\
\hline $\begin{array}{l}\text { ECO10) A Aceitação à } \\
\text { Intervenção Ambiental nas } \\
\text { Decisões }\end{array}$ & $\begin{array}{l}\text { Esse tipo de decisão se aplica ao princípio da precaução (PERRINGS, 1991; VON } \\
\text { SCHOMBERG, 2012; RICHIE; OPPENHEIMER; CLARK, 2012), para entronizar } \\
\text { ações preventivas nas decisões organizacionais (PETER; HENRIËTTE, 2010). }\end{array}$ \\
\hline $\begin{array}{l}\text { ECO11) Políticas } \\
\text { Econômicas que possam } \\
\text { Suavizar o Preço dos } \\
\text { Produtos }\end{array}$ & $\begin{array}{l}\text { Os agentes econômicos têm alto custo ambiental de aquisição de suprimentos, } \\
\text { mas podem aderir a ferramentas de ecoeficiência no processo produtivo, como } \\
\text { a produção mais limpa, que resulta em vantagens econômicas por reduzir } \\
\text { desperdícios, possibilitando manter o preço competitivo (EHRENFELD, 2005). }\end{array}$ \\
\hline $\begin{array}{l}\text { ECO12) Avaliação das } \\
\text { Vantagens Econômicas das } \\
\text { práticas Ambientais }\end{array}$ & $\begin{array}{l}\text { Os agentes econômicos devem mensurar as vantagens ambientais e econômicas } \\
\text { da ecoeficiência no processo produtivo (BRATTEBO, 2005; BURRUTT; SAKA, } \\
\text { 2006). }\end{array}$ \\
\hline $\begin{array}{l}\text { ECO13) A Redução de } \\
\text { Desperdícios devido a } \\
\text { Mudanças de Processos }\end{array}$ & $\begin{array}{l}\text { Os agentes econômicos visam à redução do desperdício, considerado princípio } \\
\text { enxuto, nas mudanças dos processos (HASLE, 2012). }\end{array}$ \\
\hline $\begin{array}{l}\text { ECO14) Indicadores } \\
\text { Sustentáveis de Bolsa de } \\
\text { Valores }\end{array}$ & $\begin{array}{l}\text { A redução do fator de risco, avaliado no indicador Dow Jones de Sustentabilidade, } \\
\text { torna muitos empreendimentos mais atrativos aos investidores (MENZ, 2010). }\end{array}$ \\
\hline $\begin{array}{l}\text { ECO15) Avaliação do Preço } \\
\text { dos Produtos Ecologicamente } \\
\text { corretos visando à } \\
\text { transparência }\end{array}$ & $\begin{array}{l}\text { As empresas não governamentais (DashboardofSustainability - Painel de } \\
\text { Sustentabilidade) e (DOW JONES..., 2013) acompanham o desempenho econômico } \\
\text { de empresas líderes em sustentabilidade, verificando o processo de comercialização } \\
\text { e o preço dos produtos ecológicos para tornar as informações transparentes. }\end{array}$ \\
\hline $\begin{array}{l}\text { ECO16) Mostrar para a } \\
\text { sociedade os Custos de } \\
\text { Controle da Poluição e } \\
\text { preservação ambiental }\end{array}$ & $\begin{array}{l}\text { A estrutura (DOW JONES..., 2013) visa à transparência sobre o código de conduta, } \\
\text { na qual deixa público o custo ambiental da organização. Segundo Yates (2012), é } \\
\text { fundamental transparecer o custo ambiental para o controle da poluição. }\end{array}$ \\
\hline
\end{tabular}


Quadro 3. Influências exercidas pela sociedade para a implementação da Produção Mais Limpa.

\begin{tabular}{|l|l|}
\hline \multicolumn{1}{|c|}{ Influências } & \multicolumn{1}{c|}{ Conceito } \\
\hline $\begin{array}{l}\text { SOC1) Aceita Pagar mais Caro } \\
\text { pelos Produtos Ecologicamente } \\
\text { corretos }\end{array}$ & $\begin{array}{l}\text { A sociedade aceita pagar mais caro por produtos ecológicos (LAROCHE; } \\
\text { BERGERON; BARBARO-FORLEO, 2001; MANAKTOLA; JAUHARI, 2007; } \\
\text { HAN; HSU; LEE, 2009; HAN; KIM, 2010). }\end{array}$ \\
\hline $\begin{array}{l}\text { SOC2) Mostra a Mudança de } \\
\text { Valores e a disseminação do } \\
\text { Comportamento Ambiental }\end{array}$ & $\begin{array}{l}\text { A sociedade está aderindo a valores ambientais, modificando o comportamento de } \\
\text { compra (PICKETT-BAKER; OZAKI, 2008). }\end{array}$ \\
\hline $\begin{array}{l}\text { SOC3) Reorganização Crítica } \\
\text { de seu Conhecimento acerca } \\
\text { de aspectos que visam à } \\
\text { preservação do planeta }\end{array}$ & $\begin{array}{l}\text { A sociedade passa por um momento de reflexão crítica a respeito da preservação } \\
\text { do ecossistema, assumindo o direito ambiental como aspecto essencial da } \\
\text { qualidade de vida (CARRETE et al., 2012; MARKKULA; MOISANDER, 2012; } \\
\text { CHITAKORNKIJSIL, 2012). }\end{array}$ \\
\hline $\begin{array}{l}\text { SOC4) A Refutar ou Denunciar } \\
\text { Práticas Enganosas. }\end{array}$ & $\begin{array}{l}\text { A sociedade tem preferências ambientais na compra de produtos e serviços que } \\
\text { mitigam poluição e estão atentos a práticas enganosas (LEVITT; LIST, 2007). }\end{array}$ \\
\hline $\begin{array}{l}\text { SOC5) Exigência de um } \\
\text { Serviço de Atendimento à } \\
\text { Sociedade a fim de evitar } \\
\text { a propaganda enganosa, } \\
\text { estimular denúncias de práticas } \\
\text { ilegais sobre o Meio Ambiente }\end{array}$ & $\begin{array}{l}\text { Conhecer o comportamento crítico da sociedade em relação à sustentabilidade } \\
\text { consiste numa ferramenta de sobrevivência para as organizações } \\
\text { (CHITAKORNKIJSIL, 2012). O canal de relacionamento com a sociedade } \\
\text { é a principal maneira de pressionar as organizações a práticas genuínas de } \\
\text { preservação do planeta (HEAL, 2000). }\end{array}$ \\
\hline
\end{tabular}

Portanto, a influência dos stakeholders tem impulsionado a governança corporativa das organizações a realizar investimento socialmente responsável em práticas de $\mathrm{P}+\mathrm{L}$, resultando em melhor desempenho ambiental. Entretanto, os investimentos em $\mathrm{P}+\mathrm{L}$ variam de país para país devido à disponibilidade de capital, ao estágio de desenvolvimento dos sistemas bancários, à existência de mecanismos de financiamento adequados, tecnologia e know-how (ORTAS; BURRITT; MONEVA, 2013). Foram encontrados quatro estudos dessa origem no cenário brasileiro, voltados à adesão de responsabilidade socioambiental na governança corporativa (COUTINHO; MACEDO-SOARES, 2002; SAUERBRONN; SAUERBRONN, 2011; ANGELO et al., 2012; JABBOUR et al., 2012).

Com fundamento em pesquisa bibliográfica e documental nas áreas de negócios, sociedade e gestão estratégica se constataram que as empresas tendem a ouvir os stakeholders (a citar: governos, empresas concorrentes, consumidores e fornecedores) e inserir atributos de sustentabilidade requeridos por estes na formulação estratégica. Entretanto, para atingir a implantação nos níveis operacionais, por exemplo, na produção, sugere-se trabalhar mudança de valores nos funcionários de forma abrangente e estratégica (COUTINHO; MACEDO-SOARES, 2002). Ficou evidente, que as governanças corporativas devem aceitar as influências de governos, de comunidades e associações de moradores, entre outras organizações da sociedade civil para a formulação de estratégia na estrutura funcional (SAUERBRONN; SAUERBRONN, 2011). Por exemplo, em um estudo de caso único realizado em uma transportadora foi demonstrada a necessidade de integração de ideias dos stakeholders para a consecução de política eficaz de gestão de resíduos no sistema de produção/serviço. É importante salientar que a governança corporativa da transportadora considerou uma variável denominada operacionalização para colocar em prática as ações planejadas, primordial no framework no processo de implantação (ANGELO et al., 2012). Em outro estudo, agora de múltiplos casos, constatou-se que todas as empresas apresentaram pelo menos uma variável voltada a treinamento interno nos ecotimes, sendo que a empresa $\mathrm{B}$ frisou a implantação de $\mathrm{P}+\mathrm{L}$ e expansão desse conceito para os fornecedores. Um resultado importante desse estudo consistiu em elucidar que apesar de as empresas terem alguns princípios da $\mathrm{P}+\mathrm{L}$ implantados na governança, visando atender aos preceitos dos stakeholders, ainda mostra incipiência de ação, denotando oportunidade significativa das empresas se engajarem nesse objetivo (JABBOUR et al., 2012).

A governança corporativa tem por objetivo transparecer confiança, ética, moral, novos valores para os stakeholders, incluindo o governo, a sociedade e os empresários, visando preocupação com as ações da organização, e as consequências dessas ações (HERMALIN, 2005; KOCMANOVA et al., 2011). Desta forma, a empresa que quiser elucidar uma compreensão da sustentabilidade aborda essas questões de maneira mais completa pela governança corporativa, como é o caso de incrementar práticas de sustentabilidade na produção de bens (ARAS; CROWTHER, 2008). O elemento crucial para alcançar as metas em todas as áreas acima mencionadas é a Governança Corporativa, que deve considerar os interesses dos stakeholders para a formulação da estratégia de negócios para integrar os esforços de 
todas as três áreas (ambiental, social e econômica) nas áreas funcionais da empresa (KOCMANOVA et al., 2011).

A governança corporativa visa à criação de equilíbrio entre os objetivos econômicos e sociais de uma empresa, incluindo aspectos como o uso eficiente de recursos, prestação de contas no uso de seu poder, e o comportamento da corporação em seu ambiente social (SETHI, 2002). A definição da boa governança corporativa ainda está sujeita a debate. No entanto, a boa governança corporativa irá abordar tais pontos como a criação de valor sustentável por meio da produção de bens ecológicos atingirem as metas da empresa e manter um equilíbrio entre o econômico e benefício social. Além disso, a boa governança oferece alguns benefícios a longo prazo para a empresa, como a redução de riscos, atração de novos investidores, acionistas com mais equidade (ARAS; CROWTHER, 2008). No Quadro 4, fundamentaram-se 16 princípios da governança corporativa que tendem a entronizar a formulação da estratégia corporativa com desdobramento na área operacional.

\section{Metodologia}

O modelo teórico-conceitual adotado na pesquisa pressupõe que as influências dos stakeholders denominadas como influências exógenas, compostas pelos constructos Políticas Públicas, Agentes Econômicos e Sociedade influenciam a determinação de uma Governança Corporativa que incorpora estrategicamente a $\mathrm{P}+\mathrm{L}$ como um paradigma de geração de valor para a empresa.

$\mathrm{O}$ método de pesquisa utilizado consiste no levantamento do tipo survey exploratório (FORZA, 2002), por explorar as possíveis influências ambientais da política pública, agentes econômicos e sociedade sobre a governança corporativa das empresas, que convertem essas influências em práticas de produção mais limpa. Os achados dessa pesquisa permitiram mapear relações inter e intraconstructos e ainda testar a hipótese de que os stakeholders influenciam positivamente a governança corporativa das empresas à definição de práticas de sustentabilidade para a produção.

A Figura 2 ilustra o modelo teórico conceitual adotado nesta pesquisa.

As unidades de análise adotadas foram empresas que se dizem comprometidas com a sustentabilidade e associadas ao Instituto Ethos, uma entidade criada e mantida por um grupo de empresas interessadas em promover o desenvolvimento sustentável. O total das empresas associadas ao instituto é de 1512. A amostra utilizada foi a não probabilística e intencional, cujos critérios de seleção foram: 1) marca conhecida;2) site institucional que menciona aspectos de sustentabilidade; e 3) ser composta por diferentes ramos de atividade, visando principalmente indústrias manufatureiras. O tamanho da amostra foi definido segundo Rea e Parker (1997), para pequenas populações selecionadas. Com base na lista de empresas do Instituto Ethos e nos três critérios estabelecidos, foram selecionadas 106 empresas para envio do questionário.

Os dados foram obtidos por meio de um questionário estruturado, composto em sua maioria por questões fechadas. Para mensurar os indicadores de cada constructo (influências dos stakeholders) foi utilizada uma escala dicotônica nominal, cujas opções visaram identificar se o gestor de operações ou gestor ambiental da empresa considerava como tendência as variáveis que compunham cada constructo. A adequação do questionário foi realizada em um pré-teste, em quatro empresas para adequação quanto ao número de questões, linguagem utilizada nas questões e duração do preenchimento.

O questionário foi elaborado com cinco seções: (a) dados descritivos da empresa; (b) questões relativas à influência dos 22 indicadores relacionados ao

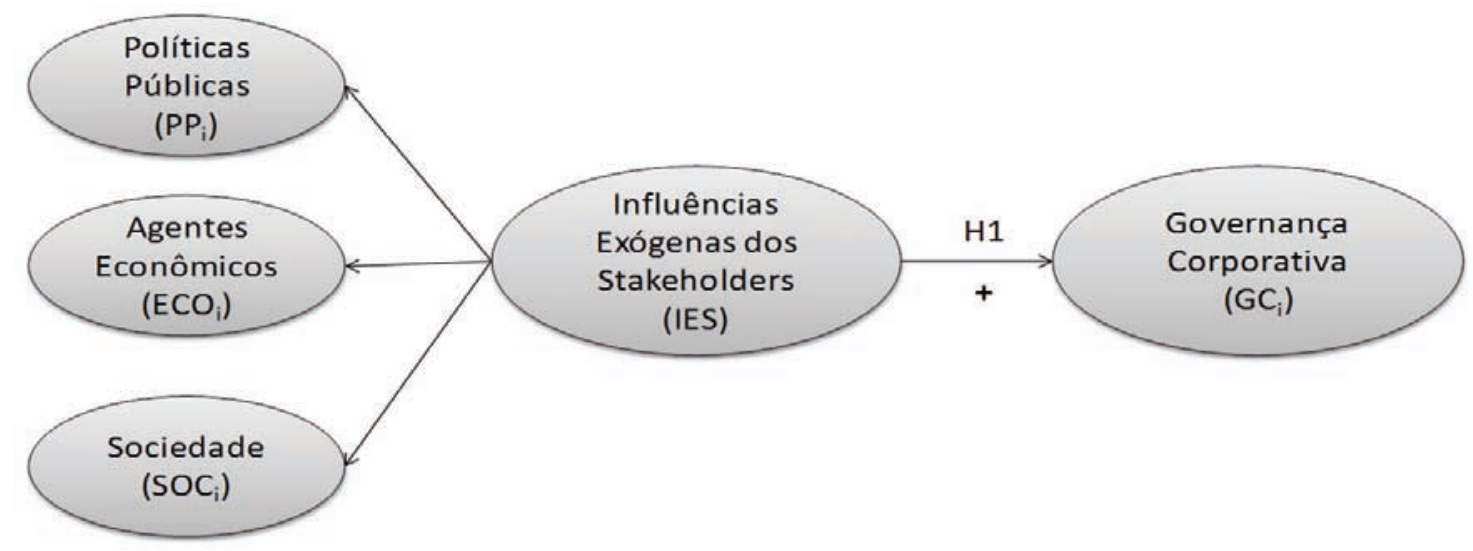

Figura 2. Modelo teórico conceitual da pesquisa. 
Quadro 4. Princípios de uma governança corporativa voltada à Produção Mais Limpa.

\begin{tabular}{|l|}
\hline \multicolumn{1}{|c|}{ Influências } \\
\hline GC1) Implementação de estratégia para \\
sustentabilidade com gestão participativa \\
objetivando mudanças na visão, missão e \\
valores da organização
\end{tabular}

A governança corporativa precisa adotar a estratégia para sustentabilidade para industrialização de bens e serviços, considerando as variáveis: econômica, cultural, ambiental e social (YU, 2012).

O ecotime é um grupo de trabalho formado por profissionais da empresa pela alta administração que tem por objetivo conduzir o programa de produção mais limpa. Suas principais funções são: realizar o diagnóstico dos setores, implantar o programa, identificar oportunidades, implementar indicadores nos processos, monitorar o programa e implementar melhorias contínuas (SERVIÇO..., 2003). As pessoas são os recursos principais para uma abordagem participativa e preventiva em relação à sustentabilidade (NEVENS et al., 2008).

GC3) Existência de departamento de A governança corporativa deve estruturar as políticas de gestão gestão ambiental ambiental visando reduzir riscos ambientais (TRIPATHY, 2011).

GC4) Sistema de gestão ambiental (SGA) com auditorias nos processos organizacionais

É necessário estabelecer auditoria ambiental com o objetivo de avaliar a efetividade do SGA. O objetivo principal é levantar e avaliar todos os impactos ambientais existentes na indústria (TRIPATHY, 2011; RADU, 2012).

GC5) Disseminar a educação ambiental para os colaboradores e comunidades

A governança precisa intensificar a comunicação, mostrando transparência da responsabilidade ambiental da empresa, envolvendo os colaboradores, comunidades e clientes (BRAVO; MATUTE; PINA, 2012; GLASS, 2012).

GC6) Transparecer a ética sobre os fatores ambientais da organização na mídia

A governança deve adotar como mecanismo estratégico a transparência ética de suas ações ambientais nos veículos de comunicação e relatório de sustentabilidade visando à vantagem competitiva (GLASS, 2012; BRAVO; MATUTE; PINA, 2012).

GC7) Disseminar informações sobre os produtos ecologicamente corretos, visando preços compatíveis com plena disponibilidade

A governança corporativa precisa transparecer informações sobre os produtos ecológicos (FREEMAN; HASNAOUI, 2011; GLASS, 2012; BRAVO; MATUTE; PINA, 2012). Para obter preços compatíveis é necessário aumentar a demanda de produção (HEAL, 2000).

GC8) Avaliar se o roteiro de atividades está sendo cumprido pelos setores

A governança estabelece um roteiro de ação para melhorias ambientais nos setores (SERVIÇO..., 2003). As melhorias são: desenvolvimento de processos, implantação de inovações preventivas, implantação de SGA com avaliação do ciclo de vida dos produtos, ecodesign e relatório de sustentabilidade (STANISKIS; ARBACIAUSKAS; VARZINSKAS, 2012).

GC9) Analisar os documentos dos processos e planos de ação para Os documentos e processos sobre sustentabilidade devem ser avaliados pela governança da empresa com foco: (i) técnico, em relação à melhorias nos setores produtividade, segurança e treinamento; (ii) ambiental, sobre a utilização de recursos naturais; e (iii) econômico, sobre os custos e retorno sobre o investimento (SERVIÇO..., 2003), factível a auditorias ambientais (TRIPATHY, 2011; RADU, 2012).

GC10) Relatório de sustentabilidade A governança deve comunicar os resultados das práticas ambientais por meio do relatório de sustentabilidade, se tornando aspecto de competitividade (GLASS, 2012; LACKMANN; ERNSTBERGER; STICH, 2012).

GC11) A implementação da norma (INTERNATIONAL..., 2004) e auditorias na governança A governança precisa participar na implantação da ISO 14000 para melhorar o desempenho ambiental (INTERNATIONAL..., 2004), além de promover auditorias ambientais para avaliar a efetividade (TRIPATHY, 2011; RADU, 2012).

GC12) A implementação da norma sobre rotulagem ambiental e mudanças climáticas na governança

A governança tende a implantar a rotulagem ambiental fundamentada na ISO 14020, parte da certificação (INTERNATIONAL..., 2004) para garantir que os produtos e serviços sejam comercializados em nível internacional, impulsionando maior engajamento dos envolvidos (ABBOTT; SNIDAL, 2010; STEURER, 2010). 
Quadro 4. Continuação...

\begin{tabular}{|l|l|}
\hline \multicolumn{1}{|c|}{ Influências } & \multicolumn{1}{c|}{ Conceito } \\
\hline $\begin{array}{l}\text { GC13) A implementação de normas } \\
\text { (ACCOUNTABILITY, 2003) sobre a } \\
\text { inclusão dos stakeholders nas decisões } \\
\text { da governança }\end{array}$ & $\begin{array}{l}\text { Essa ferramenta apresenta cinco fases: planejamento, contabilidade, } \\
\text { auditoria, integração dos sistemas de gestão ambiental e engajamento } \\
\text { dos stakeholders nas decisões da governança (ACCOUNTABILITY, } \\
\text { 2003). }\end{array}$ \\
\hline $\begin{array}{l}\text { GC14) Avaliar por meio da pesquisa de } \\
\text { satisfação dos clientes conhecimentos } \\
\text { sobre sustentabilidade }\end{array}$ & $\begin{array}{l}\text { Incrementar, no instrumento de pesquisa de satisfação de clientes, } \\
\text { a avaliação sobre conhecimentos de sustentabilidade. Segundo } \\
\text { CHITAKORNKIJSIL (2012), é importante a análise crítica e se as ações } \\
\text { éticas da organização estão transparentes. }\end{array}$ \\
\hline $\begin{array}{l}\text { GC15) Avaliar se aumentam as dúvidas } \\
\text { dos clientes sobre os produtos ecológicos }\end{array}$ & $\begin{array}{l}\text { A governança precisa verificar se os clientes estão mais críticos e } \\
\text { dispostos a comprar produtos ecológicos (CARRETE et al., 2012). } \\
\text { Essa avaliação é importante para nortear desenvolvimentos de produtos } \\
\text { ecológicos ou não. }\end{array}$ \\
\hline $\begin{array}{l}\text { GC16) Avaliar se ocorre acréscimo nas } \\
\text { vendas após campanha de marketing } \\
\text { verde }\end{array}$ & $\begin{array}{l}\text { Depois da campanha do Marketing verde é importante avaliar se a } \\
\text { sociedade comprou produtos ecológicos (LAROCHE; BERGERON; } \\
\text { BARBARO-FORLEO, 2001; MANAKTOLA; JAUHARI, 2007; HAN; } \\
\text { HSU; LEE, 2009; HAN; KIM, 2010). }\end{array}$ \\
\hline
\end{tabular}

constructo políticas públicas; (c) questões relativas à influência dos 16 indicadores relacionados ao constructo agentes econômicos; (d) questões relativas à influência dos cinco indicadores relacionados ao constructo sociedade; (e) 16 questões relativas aos princípios de uma governança corporativa voltada à $\mathrm{P}+\mathrm{L}$ seguidos pela empresa.

O convite de preenchimento do questionário foi enviado por $e$-mail para as empresas da amostra, com o campo assunto intitulado "Encaminhar para o setor de comunicação corporativa, por favor". No corpo do texto do $e$-mail foram explanados sucintamente os objetivos, com a opção de concordância ou não com a pesquisa e o link para o preenchimento do questionário. Para a construção e desenvolvimento do questionário e o respectivo banco de dados, foi utilizada a plataforma do Google (google docs).

Foi realizado um teste de confiabilidade da escala por meio do Alfa de Cronbach. Num primeiro momento, a Análise de Componentes Principais, com dimensionamento ótimo não linear para dados ordinais e nominais - CATPCA foi utilizada com um propósito exploratório, na tentativa de reduzir as variáveis originais dos constructos mencionados no modelo teórico-conceitual, de forma que os componentes principais mais importantes expliquem a maior parcela da variância da massa de dados originais. (LATTIN; CARROLL; GREEN, 2003).

A Análise de Componentes Principais (CPA) tradicionalmente é empregada em variáveis quantitativas. Por outro lado, a CATPCA torna-se uma opção interessante nas pesquisas em gestão de operações que envolvam variáveis qualitativas categóricas ou nominais, como é o caso do presente trabalho.
Para analisar de forma multivariada tais variáveis qualitativas na CATPCA, são atribuídas quantificações numéricas às categorias de cada uma das variáveis qualitativas, possibilitando, posteriormente, uma análise das componentes principais para as variáveis assim transformadas (MEULMAN, 1992, 1998). Os valores numéricos atribuídos a cada uma das classes das variáveis originais são definidos por um procedimento interativo denominado método dos mínimos quadrados alternado, de tal modo que as quantificações numéricas possuam propriedades métricas (MEULMAN, 1992, 1998; MEULMAN; VAN DER KOOIJ; HEISER, 2004; MOROCO, 2003).

O procedimento de análise dos dados consistiu na realização de etapas:

- Redução do número de variáveis de cada um dos constructos por meio da CATPCA. Para esta etapa, foram adotados os seguintes parâmetros para a realização da CATPCA, conforme ilustra o Quadro 5.

- Aplicação da CATPCA aos quatro constructos simultâneos a fim de se identificar possíveis relações entre as Influências Exógenas dos Stakeholders (variável latente) e a Governança Corporativa (variável latente). Os critérios usados na CATPCA desta fase foram os mesmos ilustrados no Quadro 5.

- Validação da Hipótese central do trabalho.

\section{Resultados e discussão}

Cento e duas empresas (52\% do total) retornaram os questionários totalmente preenchidos (Quadro 1). Desta forma, foram excluídos quarenta e sete casos. A Tabela 1 resume as estatísticas descritivas da amostra final, tratada e readequada. 
Quadro 5. Parâmetros adotados para a realização da CATPCA.

\begin{tabular}{|l|l|}
\hline \multicolumn{1}{|c|}{ Parâmetro } & \multicolumn{1}{c|}{ Descrição } \\
\hline Adequação da amostra & $\begin{array}{l}\text { KMO maior que 0,6; Índice de Esfericidade de Barlett (p<0,05); e } \\
\text { eliminação das variáveis com correlação anti-imagem menor que 0,5 }\end{array}$ \\
\hline Definição da escala ideal e ponderação & Escala spline nominal, grau 2, nós internos: 0 e ponderação da variável: 1,0 \\
\hline Discretização & Método de classificação \\
\hline Método de normalização: & Principal da variável \\
\hline Número de fatores ou componentes & $\begin{array}{l}\text { Critério de Kaiser (Componentes cujo autovalor está acima de } 1,0) \text { e } \\
\text { variância explicada dos componentes principais acumulados acima de 50\% }\end{array}$ \\
\hline $\begin{array}{l}\text { Critério de seleção das variáveis de } \\
\text { cada componente principal }\end{array}$ & Carga fatorial acima de 0,60 \\
\hline
\end{tabular}

Tabela 1. Estatística Descritiva da amostra tratada.

\begin{tabular}{|c|c|c|c|c|}
\hline Setor & Enviados & Respondidos & Eliminados & Amostra final \\
\hline Metalurgia & 16 & 14 & 0 & 14 \\
\hline Química & 15 & 14 & 3 & 11 \\
\hline Consultoria em manufatura & 9 & 9 & 0 & 9 \\
\hline Alimentício & 7 & 7 & 0 & 7 \\
\hline Eletroeletrônico & 5 & 4 & 0 & 4 \\
\hline Papel e celulose & 4 & 3 & 1 & 2 \\
\hline Automobilístico & 4 & 4 & 4 & 0 \\
\hline Farmacêutico & 6 & 4 & 0 & 4 \\
\hline Cosméticos & 4 & 4 & 2 & 2 \\
\hline Gráfica & 5 & 3 & 1 & 2 \\
\hline Confecções & 3 & 3 & 3 & 0 \\
\hline Construção civil & 3 & 3 & 3 & 0 \\
\hline Autopeças & 3 & 3 & 3 & 0 \\
\hline Ferragens/Fechadura & 2 & 2 & 2 & 0 \\
\hline Higiene/ Limpeza & 2 & 2 & 2 & 0 \\
\hline Produtos Hospitalares & 2 & 2 & 2 & 0 \\
\hline Tecnologia da Informação & 2 & 2 & 2 & 0 \\
\hline Educacional & 2 & 2 & 2 & 0 \\
\hline Varejo & 1 & 1 & 1 & 0 \\
\hline Móveis & 1 & 1 & 1 & 0 \\
\hline Offshore & 1 & 1 & 1 & 0 \\
\hline Imagem & 1 & 1 & 1 & 0 \\
\hline Automação & 1 & 1 & 1 & 0 \\
\hline Artefato de Borracha & 1 & 1 & 1 & 0 \\
\hline Produtos Florestais & 1 & 1 & 1 & 0 \\
\hline Agronegócio & 1 & 1 & 1 & 0 \\
\hline Lápis & 1 & 1 & 1 & 0 \\
\hline Petroquímica & 1 & 1 & 1 & 0 \\
\hline Bens de Consumo & 1 & 1 & 1 & 0 \\
\hline Sucroalcooleiro & 1 & 1 & 1 & 0 \\
\hline Total & 106 & 102 & 47 & 55 \\
\hline
\end{tabular}

\subsection{Redução das variáveis de cada constructo}

Na Tabela 2, mostra-se que a política pública tende a exercer maior influência (14) sobre as organizações para a implantação da $\mathrm{P}+\mathrm{L}$, seguida de 10 influências exógenas dos agentes econômicos e apenas 4 exercidas pela sociedade, que serão explicadas em seguida.

O constructo Políticas Públicas foi composto por 14 influências, distribuídas em 4 componentes e representando $57,3 \%$ da variância total (Tabela 2). Os dados mostram que: 
Tabela 2. Redução do número de variáveis por constructo, influências e princípios, variância respectiva e taxa de redução das variáveis.

\begin{tabular}{|c|c|c|c|c|}
\hline Constructos & Variáveis Selecionadas & $\begin{array}{c}\text { Número de } \\
\text { Componentes } \\
\text { Principais }^{1}\end{array}$ & $\begin{array}{c}\text { Variância Explicada } \\
\text { nos Componentes } \\
\text { Selecionados }(\%)\end{array}$ & $\begin{array}{c}\text { Taxa de } \\
\text { redução de } \\
\text { variáveis }\end{array}$ \\
\hline Políticas Públicas (PP) & $\begin{array}{l}\mathrm{PP}_{2} ; \mathrm{PP}_{3} ; \mathrm{PP}_{5} ; \mathrm{PP}_{6} ; \mathrm{PP}_{9} ; \mathrm{PP}_{11-} \\
{ }_{17} ; \mathrm{PP}_{20} ; \mathrm{PP}_{22}\end{array}$ & 4 & $57,3 \%$ & $36 \%$ \\
\hline $\begin{array}{l}\text { Agentes Econômicos } \\
(\text { ECO) }\end{array}$ & $\begin{array}{l}\mathrm{ECO}_{1-3} ; \mathrm{ECO}_{5} ; \mathrm{ECO}_{7} ; \mathrm{ECO}_{9} ; \\
\mathrm{ECO}_{10} ; \mathrm{ECO}_{11} ; \mathrm{ECO}_{15} ; \mathrm{ECO}_{16}\end{array}$ & 4 & $55,5 \%$ & $38 \%$ \\
\hline Sociedade (SOC) & $\mathrm{SOC}_{2-5}$ & 2 & $69,2 \%$ & $20 \%$ \\
\hline $\begin{array}{l}\text { Governança } \\
\text { Corporativa (GC) }\end{array}$ & $\mathrm{GC}_{1-4} ; \mathrm{GC}_{10-13} ; \mathrm{GC}_{15}$ & 3 & $63,9 \%$ & $44 \%$ \\
\hline \multirow[t]{3}{*}{ Estatísticas } & & Média & $61,5 \%$ & $34 \%$ \\
\hline & & Desvio padrão & $6,3 \%$ & $10,1 \%$ \\
\hline & & Mediana & $60,6 \%$ & $37 \%$ \\
\hline
\end{tabular}

${ }^{1}$ Com autovalores maiores que 1,0 .

(i) 5 influências estão associadas a estímulos e penalizações financeiras sobre as organizações para implementação da $\mathrm{P}+\mathrm{L}: \mathrm{PP}_{2}$ - redução de impostos (WANGLER, 2012), $\mathrm{PP}_{5}$ indenização sobre a extração de recursos naturais (HAUBRICH, 2004), $\mathrm{PP}_{12}$ - taxação sobre emissões de carbono (SCANDIZZO; KNUDSEN, 2012) e $\mathrm{PP}_{13}$ - despejo de efluentes poluidores (LYON; JOHN, 2003), e $\mathrm{PP}_{22}$ avaliação da compra de produtos ecológicos (LEE, 2006).

(ii) 4 influências visam disseminar a educação ambiental para as indústrias: $\mathrm{PP}_{6}$ - transparecer ações ambientais (VACCARO; ECHEVERRI, 2010) e $P_{16,17,20}$ - estimular a conscientização (YARIME et al., 2012).

(iii) 3 influências objetivam auditar a produção: $\mathrm{PP}_{3,14}$ - exigência de tecnologias limpas (WANGLER, 2012) e $\mathrm{PP}_{11}$ - monitoração ambiental (DÉNIZDÉNIZ; GARCIA-FALCON, 2002).

(iv) 2 influências visam criar legislação para o controle ambiental: $\mathrm{PP}_{9}$ - com tribunal arbitral (LIMA, 2010) para o $\mathrm{PP}_{15}$ - o controle dos agentes poluidores (SEIFFERT, 2010).

O constructo Agentes Econômicos foi composto por 10 influências, distribuídas em 4 fatores, representando uma variância acumulada total de $55,5 \%$. Os dados apontam que:

(i) 4 influências mencionam que a $\mathrm{P}+\mathrm{L}$ resulta em vantagem econômica: $\mathrm{ECO}_{2}$ - geração de valor em marca e reputação (ZAMAGNI, 2009), $\mathrm{ECO}_{3}$ - redução de desperdícios (KNIGHT; JENKINS, 2009), $\mathrm{ECO}_{5}$ - facilidade de financiamento (BHATTACHARYYA, 2007); e $\mathrm{ECO}_{7}$ - facilidade do uso de (MDL)(LI; COLOMBIER, 2011).

(ii) 3 influências visam à economia ecológica: $\mathrm{ECO}_{1,9}$ - o custo ambiental é considerado investimento (ZAHARIA; ZAHARIA, 2012) com $\mathrm{ECO}_{10}$ - ações preventivas nas decisões (PETER; HENRIËTTE, 2010).

(iii) 3 influências visam transparecer a economia ecológica aos stakeholders: $\mathrm{ECO}_{11}$-suavizar o preço dos produtos (EHRENFELD, 2005) e $\mathrm{ECO}_{15,16}$ - uso de indicadores para mostrar o custo ambiental (DOW JONES..., 2013).

O constructo Sociedade foi composto por 4 indicadores, distribuídos em 2 fatores, representando uma variância de 69,2\% (Tabela 2), que visa: $\mathrm{SOC}_{2}$ - mudança para o comportamento ambiental (PICKETT-BAKER; OZAKI, 2008), podendo até $\mathrm{SOC}_{5}$ - denunciar práticas enganosas (CHITAKORNKIJSIL, 2012).

O constructo Governança Corporativa, composto por 9 indicadores, distribuídos em 3 componentes principais, com variância acumulada de 63,9\% (Tabela 2) mostram que:

(i) 4 influências visam transparecer educação ambiental para os stakeholders por meio do $\mathrm{GC}_{10}$ - relatório de sustentabilidade (GLASS, 2012) das ações de $\mathrm{GC}_{1}$ - produção ecológica (YU, 2012), $\mathrm{GC}_{2}$ - ecotimes (NEVENS et al., 2008), porque $\mathrm{GC}_{15}$ - os clientes estão mais críticos e dispostos a comprar produtos ecológicos (CARRETE et al, 2012).

(ii) 3 influências visam à certificação: $\mathrm{GC}_{11}$ ISO 14001(RADU, 2012), $\mathrm{GC}_{12}$ - rotulagem ambiental (ABBOTT; SNIDAL, 2010) e $\mathrm{GC}_{13}$ - (AA1000) para inclusão dos stakeholders nas decisões (ACCOUNTABILITY, 2003). 
(iii) 2 influências impulsionam a estruturação do departamento de gestão ambiental (TRIPATHY, 2011) para $\mathrm{GC}_{4}$ - realizar auditorias (RADU, 2012).

Por fim, os critérios adotados no Quadro 1 para redução de variáveis para a CATPCA foram considerados suficientes para a realização da CATPCA sistêmica, objeto seguinte de discussão que visa compreender as possíveis relações entre as influências dos stakeholders e as práticas de Governança Corporativa.

\subsection{Identificação de relações entre Influências Exógenas dos Stakeholderse Governança Corporativa}

A Tabela 3 ilustra as cargas dos componentes principais para a análise sistêmica entre os constructos relativos às influências exógenas dos Stakeholders e a Governança corporativa.

Observando a Tabela 3, pode-se perceber que somente o primeiro componente principal evidencia possíveis relações entre Influências Exógenas dos Stakeholders e Governança Corporativa, de acordo com os critérios estabelecidos na parametrização da CATPCA. Segundo Lattin, Carrol e Green (2003), a CATPCA foi utilizada com um propósito exploratório para reduzir as variáveis em influências ou componentes principais que expliquem a maior parcela da variância da massa de dados originais (LATTIN; CARROL; GREEN, 2003). Apesar de corresponder a apenas $27, \%$ da variância total, fornece indícios que merecem ser mais bem analisados. As interpretações que se pode inferir da Tabela 3 são as seguintes:

I: Sempre que os respondentes da pesquisa apontaram que as influências $\mathrm{SOC}_{4} ; \mathrm{PP}_{22} \mathrm{e}$ $\mathrm{PP}_{12}$ eram importantes para a sua organização, os princípios da governança corporativa $\mathrm{GC}_{12}$; $\mathrm{GC}_{13}$ e $\mathrm{GC}_{15}$ apareceram como sendo adotados por essa organização.

Dessa forma, mostrou-se na presente pesquisa que as influências exógenas (i) SOC4 - a sociedade visa denunciar práticas enganosas (LEVITT; LIST, 2007); (ii) $\mathrm{PP}_{12}$ - a política pública visa taxar as emissões de gás carbônico (QU; QU, 2011); e (iii) $\mathrm{PP}_{22}$ - a política pública tende a avaliar a compra de produtos ecológicos, que (LEE, 2006) impulsionam diretamente

Tabela 3. CATPCA sistêmica entre Influências Exógenas dos Stakeholders e Governança Corporativa, contemplando os indicadores e as componentes principais.

\begin{tabular}{|c|c|c|c|c|}
\hline \multirow[t]{2}{*}{ Variáveis (Indicadores) } & \multirow[t]{2}{*}{ Sigla } & \multicolumn{3}{|c|}{$\begin{array}{l}\text { Componentes } \\
\text { Principais }\end{array}$} \\
\hline & & 1 & 2 & 3 \\
\hline A Refutar ou Denunciar Práticas Enganosas & SOC4 & 0,84 & & \\
\hline O Aumento da Venda de Produtos Ecológicos & PP22 & 0,56 & & \\
\hline $\begin{array}{l}\text { Estabelecimento de Taxas progressivas para atividades intensivas em Emissões } \\
\text { de Carbono }\end{array}$ & PP12 & 0,50 & & \\
\hline $\begin{array}{l}\text { A implementação da norma sobre rotulagem ambiental e mudanças climáticas } \\
\text { na governança }\end{array}$ & GC12 & 0,77 & & \\
\hline $\begin{array}{l}\text { A implementação de normas (ACCOUNTABILITY, 2003) sobre a inclusão dos } \\
\text { stakeholders nas decisões da governança }\end{array}$ & GC13 & 0,75 & & \\
\hline Avaliar se aumentam as dúvidas dos clientes sobre os produtos ecológicos & GC15 & 0,65 & & \\
\hline A Criação de Valor para os Acionistas no que tange à Marca e à Reputação & ECO2 & $-0,57$ & & \\
\hline Mostra a Mudança de Valores e a disseminação do Comportamento Ambiental & SOC2 & $-0,55$ & & \\
\hline A facilidade de usabilidade de Mecanismos de Desenvolvimento Limpo (MDL) & ECO7 & $-0,51$ & & \\
\hline Existência de departamento de gestão ambiental & GC3 & $-0,64$ & & \\
\hline Relatório de sustentabilidade & GC10 & $-0,57$ & & \\
\hline Mostrar para a sociedade os Custos de Controle da Poluição e preservação ambiental & ECO16 & & 0,71 & \\
\hline A Facilidade de Financiamento de recursos financeiros para o Investimento & ECO5 & & 0,56 & \\
\hline Estimular e Conscientizar sobre a Autorregulação Ambiental & PP17 & & 0,60 & \\
\hline Penalização e cobrança de Indenização sobre a Extração de Recursos Naturais & PP5 & & & 0,58 \\
\hline \multirow[t]{4}{*}{ Cobrança pelo Despejo de Efluentes Poluidores } & PP13 & & & 0,57 \\
\hline & utovalor & 6,61 & 2,87 & 1,98 \\
\hline & ariância & 27,5 & 12,0 & 8,3 \\
\hline & Imulada & 27,5 & 39,5 & 47,8 \\
\hline
\end{tabular}


a adoção de normas pela empresa $\mathrm{GC}_{12}$ - de rotulagem ambiental (INTERNATIONAL..., 2004) para garantir que os produtos e serviços sejam comercializados (ABBOTT; SNIDAL, 2010) e $\mathrm{GC}_{13}$ - a inclusão dos stakeholders nas decisões (ACCOUNTABILITY, 2003). Além disso, o cliente que denuncia práticas enganosas e a taxação pela política pública das emissões de gás carbônico faz com que a empresa estude melhor o comportamento do consumidor por meio de $\mathrm{GC}_{15}$ - avaliações sobre o potencial de compra de produtos ecológicos (CARRETE et al., 2012).

II: Sempre que os respondentes indicaram que as influências ECO2; SOC2 e ECO7 eram importantes para a sua organização, os princípios da governança corporativa GC3; GC10 apareceram como sendo adotados por essa organização. O sinal negativo não reflete comportamento menos valorizado, mas apenas que existe uma relação entre eles.

Os resultados apontaram três outras influências exógenas, a saber: (i) $\mathrm{ECO}_{2}$ - pressão dos acionistas para a implementação da $\mathrm{P}+\mathrm{L}$ com foco na geração de valor em marca e reputação (ZAMAGNI, 2009); (ii) $\mathrm{SOC}_{2}$ - comportamento ambiental da sociedade para compra (PICKETT-BAKER; OZAKI, 2008); e a (iii) $\mathrm{ECO}_{7}$ - facilidade no financiamento de baixo custo para adoção de MDL (GOMEZ-BAGGETHUN; RUIZ-PEREZ, 2011) para transferência de tecnologia limpa visando à adoção de P+L (LI; COLOMBIER, 2011) impulsionam diretamente a $\mathrm{GC}_{3}$ - existência de departamento ambiental para reduzir riscos ambientais (TRIPATHY, 2011) para disseminação da transparência ambiental por meio do relatório de sustentabilidade (GLASS, 2012).

Para validar a hipótese central deste trabalho, seguiu-se a consecução da etapa 3 .

\subsection{Validação da hipótese central do trabalho}

Os resultados apresentados na CATPCA da Etapa 2, visando testar a hipótese central (a citar: os stakeholders influenciam positivamente a governança corporativa das empresas que adotam práticas de $\mathrm{P}+\mathrm{L}$ em seus sistemas de produção), possibilitou desdobrá-la em duas outras hipóteses (H1a e H1b), conforme ilustrado na Figura 3.

Para mensuração das variáveis latentes, adotou-se como indicador quantitativo a pontuação de cada caso referente ao primeiro componente principal da respectiva variável latente. A Tabela 4 ilustra as estatísticas dos componentes gerados para geração dos indicadores das variáveis latentes.

A geração destes índices quantitativos permitiu que fosse realizada uma regressão linear para validar os relacionamentos ilustrados na Figura 3 (hipóteses h1a e h1b). A Figura 4, a seguir, ilustra a análise estrutural final que procurou validar a hipótese central do trabalho.

As duas hipóteses foram validadas significativamente (Figura 4), porém ambos os modelos apresentaram um coeficiente de determinação $\left(R^{2}\right)$ baixo, principalmente para a hipótese $H 1 b\left(R^{2}=0,26\right)$, denotando apenas tendência no contexto brasileiro, em que os stakeholders influenciam na determinação

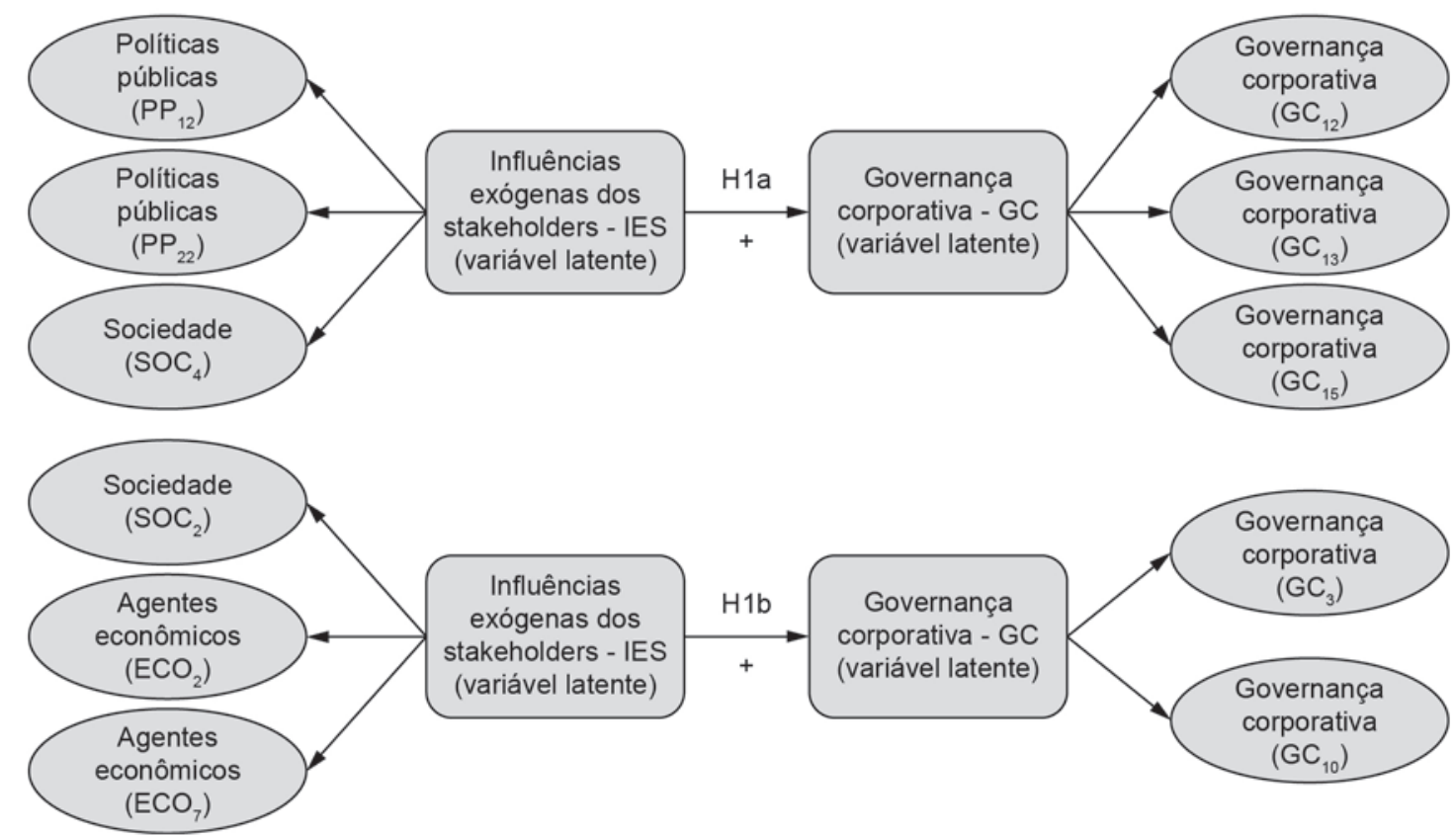

Figura 3. Desdobramento da hipótese central em duas hipóteses. 
Tabela 4. Caracterização do Primeiro Componente Principal para mensuração das variáveis latentes.

\begin{tabular}{clccc}
\hline Hipótese & $\begin{array}{c}\text { Constructo ou Variável } \\
\text { Latente }\end{array}$ & $\begin{array}{c}\text { Indicadores que formam } \\
\text { o constructo }\end{array}$ & $\begin{array}{c}\text { Autovalor do Primeiro } \\
\text { Componente Principal }\end{array}$ & $\begin{array}{c}\text { \% da Variância } \\
\text { Explicada }\end{array}$ \\
\hline H1a & $\begin{array}{l}\text { Influências Exógenas dos } \\
\text { Stakeholders (IES) } \\
\text { Governança Corporativa } \\
\text { (GC) }\end{array}$ & $\mathrm{PP}_{12} ; \mathrm{PP}_{22} ; \mathrm{SOC}_{4}$ & 1,9 & 63,1 \\
$\mathbf{H 1}$ & $\mathrm{GC}_{12} ; \mathrm{GC}_{13} ; \mathrm{GC}_{15}$ & 2,05 & 68,4 \\
& $\begin{array}{l}\text { Influências Exógenas dos } \\
\text { Stakeholders (IES) } \\
\text { Governança Corporativa } \\
\text { (GC) }\end{array}$ & $\mathrm{SOC}_{2} ; \mathrm{ECO}_{2} ; \mathrm{ECO}_{7}$ & 1,6 & 54 \\
\hline
\end{tabular}

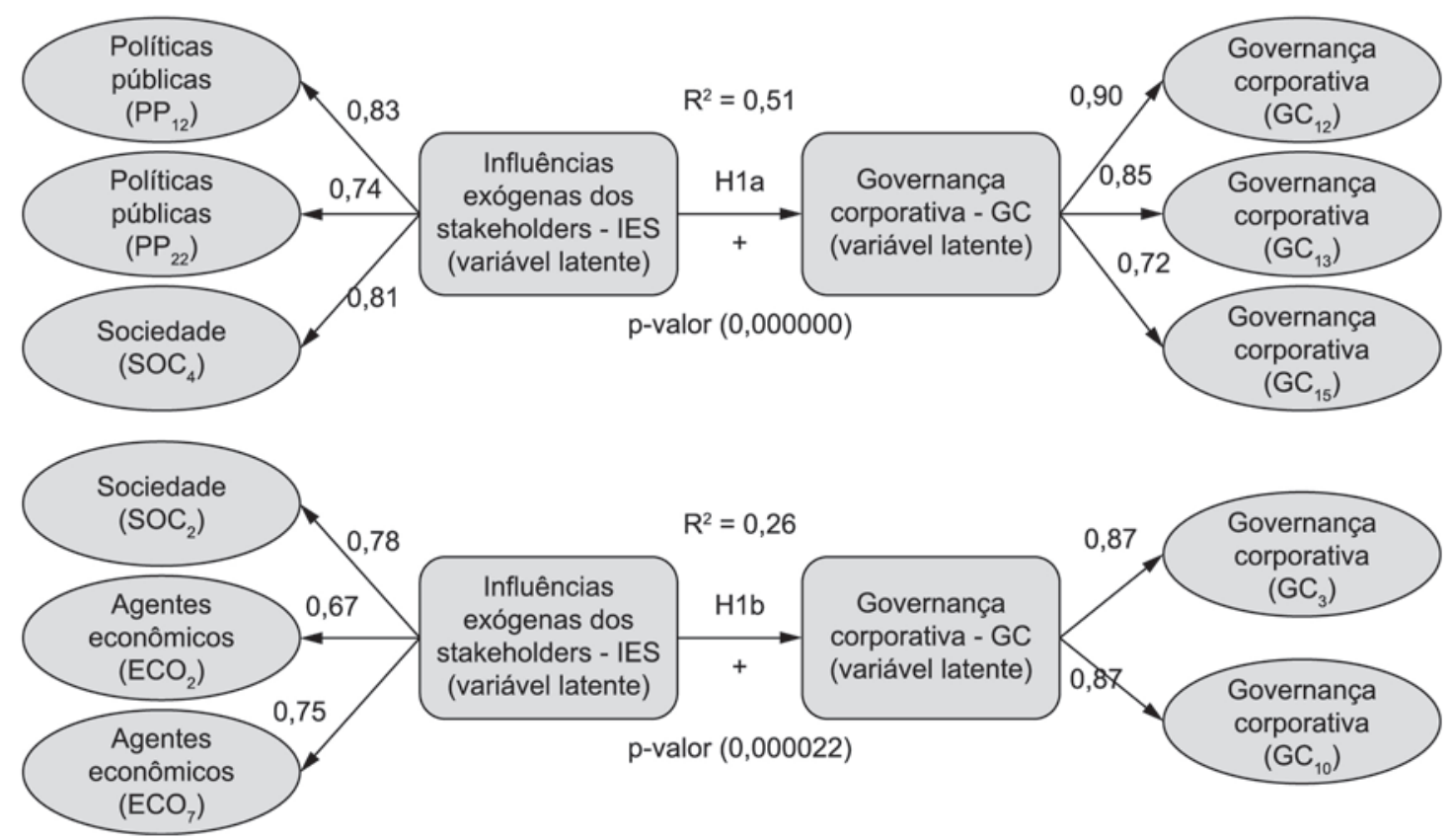

Figura 4. Resultados da análise de regressão com relação à influência exógena dos stakeholders na governança corporativa que impulsionam a implantação de P+L.

de uma política de governança corporativa que esteja alinhada aos princípios sustentáveis da $\mathrm{P}+\mathrm{L}$. Esse achado corrobora com alguns estudos internacionais, que relatam que ainda consiste em assunto em discussão, denotando tendência, em que apontam projeções (ARAS; CROWTHER, 2008; ZHANG et al., 2008; MAON; LINDGREEN; VALÉRIE SWAEN, 2010; NAVICKAS; KONTAUTIENE, 2011) e também trabalhos nacionais (COUTINHO; MACEDOSOARES, 2002; SAUERBRONN; SAUERBRONN, 2011; ANGELO et al., 2012; JABBOUR et al., 2012). Entretanto, o governo chinês parece estar mais adiantado por já ter desenvolvido orientações para as empresas mais poluidoras e principalmente proibir empresas de industrializar (SHANGHAI..., 2009; ZENG et al., 2010), com destaque para o gap de pesquisa com o objetivo de identificar quais são os principais influenciadores de uma governança corporativa para determinação da P+L (ZENG et al.,
2010). Para esse gap, constatou-se que no contexto brasileiro os influenciadores são: política pública, agentes econômicos e sociedade. O estudo de Ortas, Burritt e Moneva (2013) também corrobora com os resultados deste trabalho, em que as influências dos stakeholders variam entre países, que geralmente estão associados à disponibilidade de capital dos governos e agentes econômicos para investimentos, ou então maior facilidade de financiamento pelo governo e, principalmente, as inovações em tecnologias limpas financiadas pelos empresários e governantes.

Nos trabalhos brasileiros, constatou-se que as empresas precisam considerar as informações dos stakeholders (a citar: governos, sociedade e agentes econômicos) nas decisões funcionais formuladas pela governança corporativa. Para isso, sugere treinar os ecotimes para redução da poluição no sistema de produção (COUTINHO; MACEDO-SOARES, 2002; SAUERBRONN; SAUERBRONN, 2011), como a 
operacionalização da gestão de resíduos realizados no serviço de transporte (ANGELO et al., 2012). Entretanto, as seis empresas brasileiras pesquisadas tinham pelo menos a formação de ecotimes no sistema produtivo, porém em apenas uma empresa havia operacionalização de $\mathrm{P}+\mathrm{L}$ com projeção de expansão para os fornecedores, denotando incipiência de ação e oportunidade significativa para o engajamento socioambiental.

É possível verificar as variáveis com maior carga do componente principal que determinam a variável latente (Figura 4). No caso da hipótese H1a, percebe-se que a variável $\mathrm{PP}_{12}$ é a que possui maior carga do componente principal, seguida de $\mathrm{SOC}_{4}$ e $\mathrm{PP}_{22}$, na definição da variável latente influências exógenas dos stakeholders. Portanto, para as empresas pesquisadas, a principal influência exógena da PP para implementar $\mathrm{P}+\mathrm{L}$ consiste na taxação das emissões de carbono (SCANDIZZO; KNUDSEN, 2012), que permite conceber compensação financeira pela venda de certificados e redução de impostos a pagar (LUSTOSA, 2010), seguido do risco de denúncias de práticas enganosas pela sociedade (LEVITT; LIST, 2007), que tende a proporcionar aumento da venda de produtos ecológicos (LEE, 2006).

Ainda, referente à hipótese H1a, relativo à definição da variável latente governança corporativa, percebe-se que a variável $\mathrm{GC}_{12}$ é a que possui maior carga do componente principal, seguida de $\mathrm{GC}_{13}$ e $\mathrm{GC}_{15}$. Portanto tem-se que as influências exógenas dos stakeholders tendem a impulsionar mudanças endógenas na governança, primeiro para certificação de normas que visam à rotulagem ambiental (INTERNATIONAL..., 2004), seguida da certificação que visa à inclusão dos stakeholders nas decisões (ACCOUNTABILITY, 2003) e, por fim, a sociedade tende a ser mais crítica e ter mais disposição para comprar produtos ecológicos (CARRETE et al., 2012).

Para a hipótese H1b, percebe-se que a variável $\mathrm{SOC}_{2}$ é a que possui maior carga do componente principal, seguida de $\mathrm{ECO}_{7}$ e $\mathrm{ECO}_{2}$, na definição da variável latente influências exógenas dos stakeholders. Portanto, estima-se que a influência mais relevante da H1b é que a sociedade está aderindo a valores ambientais e isso tende a modificar o comportamento de compra (PICKETT-BAKER; OZAKI, 2008), mas a organização que aderir à $\mathrm{P}+\mathrm{L}$ poderá ter facilidade no uso de MDL (GOMEZ-BAGGETHUN; RUIZPEREZ, 2011) para realizar financiamentos a baixo custo (LI; COLOMBIER, 2011) e a criação de valor para os acionistas, em relação à marca e à reputação (ZAMAGNI, 2009).

Na definição da variável latente governança corporativa, percebe-se que a variável $\mathrm{GC}_{3}$ possui a mesma carga da variável $\mathrm{GC}_{10}$. Este comportamento, de certo modo, pode ser explicado pela baixa quantidade de variáveis e a limitação da escala dicotômica utilizada. Portanto, as influências exógenas dos stakeholders tendem a impulsionar a empresa a ter em sua estrutura um departamento para gestão ambiental (TRIPATHY, 2011), bem como a desenvolver relatórios de sustentabilidade para promover comunicação transparente com os stakeholders (GLASS, 2012).

\section{Considerações finais}

Portanto, a política pública tende a taxar emissões de carbono das empresas e, para as empresas idôneas à sustentabilidade, facilitar o financiamento a custo baixo para incentivar o desenvolvimento de projetos ecológicos; os agentes econômicos tendem a compreender a importância de produzir bens menos poluidores, além de ter que obedecer a leis ambientais com risco de autuação; e a sociedade tende a aderir ao comportamento de compra ecológica, além de denunciar práticas enganosas das empresas. Essas influências exógenas tendem a alterar os princípios da governança corporativa, que tende a considerar as opiniões dos stakeholders e melhorar a comunicação por meio do relatório de sustentabilidade, principalmente em relação à disposição de comprar produtos ecológicos dos clientes, direciona a implantação de departamento para gestão ambiental com adesão à rotulagem ambiental. Essa mudança no princípio da governança corporativa tende a impulsionar mudanças endógenas e incrementais no sistema de produção, direcionando a implantação de $\mathrm{P}+\mathrm{L}$.

Os resultados deste trabalho corroboram com outros estudos internacionais (O'ROURKE, 2003; MIRVIS; GOOGINS, 2006; ZHANG et al., 2008; SHANGHAI..., 2009; ZENG et al., 2010; MAON; LINDGREEN; VALÉRIE SWAEN, 2010; NAVICKAS; KONTAUTIENE, 2011; ORTAS; BURRITT; MONEVA, 2013) e nacionais (COUTINHO; MACEDO-SOARES, 2002; SAUERBRONN; SAUERBRONN, 2011; ANGELO et al., 2012; JABBOUR et al., 2012), tornando possível afirmar que este assunto ainda se encontra em discussão e, principalmente, de que o governo é o responsável por promover a conscientização e criação de leis para reprimir ações dos empresários e sociedade para adoção de princípios de sustentabilidade. Com isso, entende-se que a governança corporativa tenderá a direcionar esforços para a $\mathrm{P}+\mathrm{L}$ quando a política pública, agentes econômicos (empresários, acionistas) e sociedade exercer pressão a favor da sustentabilidade, como está ocorrendo no governo chinês.

A Lei de resíduos sólidos publicada em 2010 já norteia algumas exigências nesse sentido, mas ainda há incipiência de controle, permitindo o modismo das empresas. Outro aspecto relevante consiste na identificação dos principais influenciadores, denominados stakeholders. 
Em linhas gerais, as organizações apontaram que: (i) a política pública tende a promover educação ambiental e regulação, permitindo conceder estímulos financeiros para investimento; (ii) os agentes econômicos tendem a exercer pressão para a implantação da $\mathrm{P}+\mathrm{L}$ para obter ganho econômico e facilidade de investimentos para transferência de tecnologia e financiamento a baixo custo; e (iii) a sociedade tende a promover mudanças de comportamento para a compra verde, direcionando a adoção da $\mathrm{P}+\mathrm{L}$.

Estudos futuros podem avaliar as influências e princípios no nível nacional ou mesmo relacionar isso às práticas do $\mathrm{P}+\mathrm{L}$ adotadas pelas empresas. Este estudo apresenta uma limitação em relação à característica de tendência, justificada porque, apesar de os gerentes ambientais entenderem a importância das mudanças de princípios dos stakeholders e de que a governança corporativa deve estar atenta a essas mudanças para introduzir mudanças endógenas na produção de bens, o Brasil ainda encontra-se em período seminal.

\section{Referências}

ABBOTT, K. W.; SNIDAL, D. International regulation without international government: improving IO performance through orchestration. The Review of International Organizations, v. 5, n. 3, p. 315-344, 2010. http://dx.doi.org/10.1007/s11558-010-9092-3

ABREU, M. C. S.; RADOS, G. J. V.; FIGUEIREDO JUNIOR, H. S. As pressões ambientais da estrutura da indústria. RAE: Revista de Administração de Empresas, v. 3, n. 2, p. 2-22, 2004.

ACCOUNTABILITY. AA1000 Assurance Standard. London: Accountability, 2003.

ANGELO, F. D. et al. Towards a strategic CSR: a Brazilian case study. Business Strategy Series, v. 13, n. 5, p. 224-238, 2012. http://dx.doi. org/10.1108/17515631211264104

ARAS, G.; CROWTHER, D. Governance and sustainability: an investigation into the relationship between corporate governance and corporate sustainability. Management Decision, v. 46, n. 3, p. 433-448, 2008. http://dx.doi. org/10.1108/00251740810863870

BACKER, L. C. Global panopticism: states, corporations, and the governance effects of monitoring regimes. Indiana Journal of Global Legal Studies, v. 15, n. 1, p. 101-148, 2008. http://dx.doi.org/10.2979/ GLS.2008.15.1.101

BARBIERI, J. C. et al. Inovação e sustentabilidade: novos modelos e proposições. RAE: Revista de Administração de Empresas, v. 50, n. 2, p. 146-154, 2010.

BHATTACHARYYA, S. C. The White Paper on energy: will it really meet the United Kingdom's energy challenge? International Journal of Energy Sector Management, v. 1, n. 4, p. 413-424, 2007. http://dx.doi. org/10.1108/17506220710836101

BRATTEBO, H. Toward a methods framework for eco-efficiency analisis. Journal of Industrial
Ecology, v. 9, n. 4, p. 9-11, 2005. http://dx.doi. org/10.1162/108819805775247837

BRAVO, R.; MATUTE, J.; PINA, J. M. Corporate social responsibility as a vehicle to reveal the corporate identity: a study focused on the websites of spanish financial entities. Journal of Business Ethics, v. 107, n. 2, p. 129-146, 2012. http://dx.doi.org/10.1007/ s10551-011-1027-2

BRITO, R. P.; BERARDI, P. C. Vantagem competitiva na gestão sustentável da cadeia de suprimentos: um metaestudo. RAE: Revista de Administração de Empresas, v. 50, n. 2, p. 155-169, 2010.

BURRITT, R.; SAKA, C. Environmental management accounting applications and eco-efficiency: case studies from Japan. Journal of Cleaner Production, v. 14, n. 14 , p. 1262-1275, 2006. http://dx.doi.org/10.1016/j. jclepro.2005.08.012

CARRETE, L. et al. Green consumer behavior in an emerging economy: confusion, credibility, and compatibility. The Journal of Consumer Marketing, v. 29, n. 7, p. 470-481, 2012. http://dx.doi. org/10.1108/07363761211274983

CARVALHO, S. C. Sociocultural and educational factors in the sustainability of coastal zones. Management of Environmental Quality, v. 23, n. 4, p. 362-382, 2012. http://dx.doi.org/10.1108/14777831211232254

CHITAKORNKIJSIL, P. Brand integrity, advertising and marketing ethics as well as social responsibility. International Journal of Organizational Innovation, v. 4, n. 4, p. 109-130, 2012.

CHRISTMANN, P. Multinational companies and the natural environment: determinants of global environmental policy standardization. Academy of Management Journal, v. 47, n. 5, p. 747-60, 2004. http://dx.doi. org/10.2307/20159616

CIOCIRLAN, C. E.; YANDLE, B. The Political Economy of Green Taxation in OECD Countries. European Journal of Law and Economics, v. 15, n. 3, p. 203-218, 2003. http://dx.doi.org/10.1023/A:1023390126187

CONRAD, C. E.; COSTELLO, A. Long-term care insurance and public policy: an analysis of obstacles to utilization. Journal of Health and Human Services Administration, v. 24, n. 3-4, p. 431-455, 2002. PMid:15002701.

COUTINHO, R. B. G.; MACEDO-SOARES, T. D. L. A. Gestão estratégica com responsabilidade social: arcabouço analítico para auxiliar sua implementação em empresas no Brasil. Revista de Administração Contemporânea, v. 6, n. 3, p. 75-96, 2002. http://dx.doi. org/10.1590/S1415-65552002000300005

DALY, H. Sustentabilidade em um mundo lotado. Scientific American Brasil, 2005. Disponível em: <http://www2. uol.com.br/sciam/>. Acesso em: 5 ago. 2005.

DÉNIZ-DÉNIZ, M. C.; GARCIA-FALCON, J. M. Determinants of the multinationals' social response. Empirical application to international companies operating in Spain. Journal of Business Ethics, v. 38, n. 4, p. 339-370, 2002. http://dx.doi. org/10.1023/A:1016061629745

DOW JONES SUSTAINABILITY INDEXES. Dow Jones Sustainability Emerging Markets Index Guide Book. 
2013. Disponível em: 〈http://www.sustainability-indices com/images/djsi-emerging-markets-guidebook.pdf $>$. Acesso em: 13 jul. 2014.

EHRENFELD, J. Eco-efficiency: philosophy, theory, and tolls. Journal of Industrial Ecology, v. 9, n. 4, p. 6-8, 2005. http://dx.doi.org/10.1162/108819805775248070

ELKINGTON, J. Cannibals with forks: the triple bottom line of 21st century business. Oxford: Capstone, 1997. p. 402.

ELLERBROCK, M. J.; REGN, A. M. toward integrating environmental and economic education: lessons from the U.S. acid rain program. Applied Environmental Education and Communication, v. 3, n. 2, p. 79-87, 2004. http://dx.doi.org/10.1080/15330150490444223

FARLEY, J. Conservation through the economics lens. Environmental Management, v. 45, n. 1, p. 26-38, 2010. PMid:19224276. http://dx.doi.org/10.1007/ s00267-008-9232-1

FORZA, C. Survey research in operation management: a process-based perspective. International Journal of Operation \& Production Management, v. 22, n. 2, p. 152-194, 2002. http://dx.doi. org/10.1108/01443570210414310

FREEMAN, I.; HASNAOUI, A. The meaning of corporate social responsibility: the vision of four nations. Journal of Business Ethics, v. 100, n. 3, p. 419-443, 2011. http:// dx.doi.org/10.1007/s10551-010-0688-6

FREEMAN, S. Capitalism in the classical and high liberal traditions. Social Philosophy \& Policy, v. 28, n. 2, p. 19-55, 2011. http://dx.doi.org/10.1017/ S0265052510000208

FREEMAN, E.; REED, D. L. Stockholders and stakeholders: a new perspective on corporate governance. California Management Review, v. 25, n. 3, p. 88-106, 1983. http://dx.doi.org/10.2307/41165018

GARCÍA, J. B.; MENDOZA, L. A. Respuestas y opciones de los productores de subsistencia. Revista Problemas del Desarrollo, v. 162, n. 41, p. 85-102, 2010.

GIANNETTI, B. F.; ALMEIDA, C. M. B. V. Ecologia industrial: conceitos, ferramentas e aplicações. São Paulo: Edgard Blücher, 2006. p. 109.

GIBSON, K. Stakeholders and sustainability: an evolving theory. Journal of Business Ethics, v. 109, n. 1, p. 15-25, 2012. http://dx.doi.org/10.1007/ s10551-012-1376-5

GLASS, J. The state of sustainability reporting in the construction sector. Smart and Sustainable Built Environment, v. 1, n. 1, p. 87-104, 2012. http://dx.doi. org/10.1108/20466091211227070

GLAVIC, P.; LUKMAN R. Review of sustainability terms and their definitions. Journal of Cleaner Production, v. 15, n. 18, p. 1875-1885, 2007. http:// dx.doi.org/10.1016/j.jclepro.2006.12.006

GOMEZ-BAGGETHUN, E.; RUIZ-PEREZ, M. Economic valuation and the commodification of ecosystem services. Progress in Physical Geography, v. 35, n. 5, p. 613-628, 2011. http://dx.doi. org/10.1177/0309133311421708

GORDON, L. Setting the context: environmental health practitioner competencies. Journal of Environmental Health, v. 65, n. 1, p. 25-27, 2002. PMid:12148324.
GREPPERUD, S. Environmental voluntary and crowding-out effects: regulation or lissez-faire? European Journal of Law and Economics, v. 23, n. 2, p. 135-149, 2007. http://dx.doi.org/10.1007/s10657-007-9008-8

HALEY, U. C. V.; SCHULER, D. A. Government policy and firm strategy in the solar photovoltaic industry. California Management Review, v. 54, n. 1, p. 17-38, 2011. http:// dx.doi.org/10.1525/cmr.2011.54.1.17

HAN, H.; HSU, L. T.; LEE, J. S. Empirical investigation of the roles of attitudes towards green behaviours, overall image, gender, and age in hotel customers' eco friendly decision making process. International Journal of Hospitality Management, v. 28, n. 4, p. 519-528, 2009. http://dx.doi.org/10.1016/j.ijhm.2009.02.004

HAN, H.; KIM, Y. An investigation of green hotel customers' decision formation: developing an extended model of the theory of planned behavior. International Journal of Hospitality Management, v. 29, n. 4, p. 659-668, 2010. http://dx.doi.org/10.1016/j.ijhm.2010.01.001

HASLE, P. Lean and the working environment: a review of the literature. International Journal of Operations \& Production Management, v. 32, n. 7, p. 829-849, 2012. http://dx.doi.org/10.1108/01443571211250103

HAUBRICH, D. Global distributive justice and the taxation of natural resources: who should pick up the tab? Contemporary Political Theory, v. 3, n. 1, p. 48-69, 2004. http://dx.doi.org/10.1057/palgrave. cpt.9300118

HEAL, G. Nature and the marktplace: capturing the value of ecosystem services. Washington: Island Press, 2000. p. 203.

HERMALIN, B. E. Trends in corporate governance. Journal of Finance, v. 60, n. 5, p. 2351-84, 2005. http://dx.doi. org/10.1111/j.1540-6261.2005.00801.x

IBRAHIM, S. S. An alternative approach to ending economic insecurity in nigeria: the role of revolving credit association. International Journal of Economics and Financial, v. 2, n. 4, p. 395-400, 2012.

INSTITUTO BRASILEIRO DE GEOGRAFIA E ESTATÍSTICA - IBGE. IDS: Indicador de Desenvolvimento Sustentável. Rio de Janeiro: IBGE, 2004. Disponível em: <http://www.ibge.gov. br/home/geocie.shtm>. Acesso em: 20 ago. 2011.

IINTERNATIONAL ORGANIZATION FOR STANDARDIZATION - ISO. ISO 14001:2004: environmental management systems: requirements with guidance for use. Geneva: ISO, 2004.

JABBOUR, C. J. C. et al. Organizations and the United Nations Millennium Development Goals: evidence from some of the largest companies in Brazil. Humanomics, v. 28, n. 1, p. 26-41, 2012. http://dx.doi. org/10.1108/08288661211200979

JO, H.; HARJOTO, M. A. The causal effect of corporate governance on corporate social responsibility. Journal of Business Ethics, v. 106, n. 1, p. 53-72, 2012. http:// dx.doi.org/10.1007/s10551-011-1052-1

KING, A. A.; LENOX, M. J. Industry self-regulation without sanctions: the chemical industry's responsible care program. Academy of Management Journal, v. 43, n. 4, p. 698-716, 2000. http://dx.doi.org/10.2307/1556362 
KNIGHT, P.; JENKINS, J. Adopting and apllying eco-design techniques: a practitioners perspective. Journal of Cleaner Production, v. 17, n. 5, p. 549-558, 2009. http://dx.doi.org/10.1016/j.jclepro.2008.10.002

KOCMANOVA, A. et al. Sustainability: environmental, social and corporate governance performance in Czech SMEs. In: WORLD MULTI-CONFERENCE ON SYSTEMICS, CYBERNETICS AND INFORMATICS, 15., 2011, Orlando. Orlando: WMSCI, 2011. p. 94-99.

KOLK, A.; PINKSE, J. Towards strategic stakeholder management? Integrating perspectives on sustainability challenges such as corporate responses to climate change. Corporate Governance, v. 7, n. 4, p. 370-378, 2007. http://dx.doi.org/10.1108/14720700710820452

LACKMANN, J.; ERNSTBERGER, J.; STICH, M. Market reactions to increased reliability of sustainability information. Journal of Business Ethics, v. 107, n. 2, p. 111-128, 2012. http://dx.doi.org/10.1007/ s10551-011-1026-3

LAROCHE, M.; BERGERON, J.; BARBARO-FORLEO, G. Targeting consumers who are willing to pay more for environmentally friendly products. The Journal of Consumer Marketing, v. 18, n. 6, p. 5023-520, 2001. http://dx.doi.org/10.1108/EUM0000000006155

LATTIN, J.; CARROLL, J. D.; GREEN, P. E. Analysing multivariate data. Pacific Grove: Thomson Learning, 2003. p. 556.

LEE, K. H. Linking stakeholders and corporate reputation towards corporate sustainability. International Journal of Innovation and Sustainable Development, v. 6, n. 2, p. 219-235, 2012.

LEE, M. Environmental economics: a market failure approach to the commerce clause. The Yale Law Journal, v. 116, n. 2, p. 456-492, 2006. http://dx.doi. org/10.2307/20455725

LEVITT, S. D.; LIST, J. A. What do laboratory experiments measuring social preferences reveal about the real world? The Journal of Economic Perspectives, v. 21, n. 2, p. 153-174, 2007. http://dx.doi.org/10.1257/jep.21.2.153

LI, J.; COLOMBIER, M. Economic instruments for mitigating carbon emissions: scaling up carbon finance in China's buildings sector. Climatic Change, v. 107, n. 3-4, p. 567-591, 2011. http://dx.doi.org/10.1007/ s10584-010-9970-y

LIMA, B. A arbitrabilidade do dano ambiental. São Paulo: Atlas, 2010. p. 190

LIPSCY, P. Y. A casualty of political transformation? The politics of energy efficiency in the japanese transportation sector. Journal of East Asian Studies, v. 12, n. 3, p. 409-439, 2012.

LUSTOSA, M. C. J. Industrialização, meio ambiente, inovação e competitividade. In: MAY, H. P. Economia do meio ambiente: teoria e prática. 2. ed. Rio de Janeiro: Elsevier, 2010. p. 205-220.

LYON, T. P.; JOHN, W. M. Self-regulation, taxation, and public voluntary environmental agreements. Journal of Public Economics, v. 87, n. 7, p. 1453-86, 2003. http:// dx.doi.org/10.1016/S0047-2727(01)00221-3

LYRA, M. G.; GOMES, R. C.; JACOVINE, L. A. G. O papel dos stakeholders na sustentabilidade da empresa para a construção de um modelo de análise.
Revista Administração Contemporânea, v. 13, n. 1, p. 39-52, 2009.

MAIMON, D. Passaporte verde: gestão ambiental e competitividade. Rio de Janeiro: Qualymark, 1996. p. 111.

MANAKTOLA, K.; JAUHARI, V. Exploring consumer attitude and behaviour towards green practices in the lodging industry in India. International Journal of Contemporary Hospitality Management, v. 19, n. 5, p. 364-377, 2007. http://dx.doi. org/10.1108/09596110710757534

MAON, F.; LINDGREEN, A.; VALÉRIE SWAEN, V. Organizational stages and cultural phases: a critical review and a consolidative model of corporate social responsibility development. International Journal of Management Reviews, v. 12, n. 1, p. 20-38, 2010. http://dx.doi.org/10.1111/j.1468-2370.2009.00278.x

MARKKULA, A.; MOISANDER, J. Discursive confusion over sustainable consumption: a discursive perspective on the perplexity of marketplace knowledge. Journal of Consumer Policy, v. 35, n. 1, p. 105-125, 2012. http:// dx.doi.org/10.1007/s10603-011-9184-3

MEULMAN, J. J. Optimal scaling methods for multivariate categorical data analysis. Chicago: SPSS, 1998. p. 1-12. (SPSS White Paper).

MEULMAN, J. The integration of multidimensional scaling and multivariate analysis with optimal transformation of variables. Spychometrica, v. 57, n. 4, p. 539-565, 1992. http://dx.doi.org/10.1007/BF02294419

MEULMAN, J. J.; VAN DER KOOIJ, A. J.; HEISER, W. J. Principal components analysis with nonlinear optimal scaling transformations for ordinal and nominal data. In: KAPLAN, D. (Ed.). Handbook of quantitative methods in the social sciences. Newbury Park: Sage, 2004. p. 49-70. http://dx.doi.org/10.4135/9781412986311.n3

MOROCO, J. Análise estatística com utilização do SPSS. Lisboa: Sílabo, 2003. p. 824. PMid:22390502 PMCid:PMC3487676.

MCBRIDE, C. M. et al. Health behavior change: can genomics improve behavioral adherence? American Journal of Public Health, v. 102, n. 3, p. 401-405, 2012. http://dx.doi.org/10.2105/AJPH.2011.300513

MCCHESNEY, R. W. This isn't what democracy looks like. Monthly Review, v. 64, n. 6, p. 1-28, 2012.

MENZ, K. M. Corporate social responsibility: is it rewarded by the corporate bond market? A critical note. Journal of Business Ethics, v. 96, n. 1, p. 117-134, 2010. http:// dx.doi.org/10.1007/s10551-010-0452-y

MIRVIS, P.; GOOGINS, B. Stages of corporate citizenship. California Management Review, v. 48, n. 1, p. 104-126, 2006. http://dx.doi.org/10.2307/41166340

NEVENS, F. et al. 'On tomorrow's grounds', Flemish agriculture in 2030: a case of participatory translation of sustainability principles into a vision for the future. Journal of Clean Production, v. 16, n. 10, p. 1062-1070, 2008. http://dx.doi.org/10.1016/j. jclepro.2007.06.007

NAVICKAS, V.; KONTAUTIENE, R. Strategical perspective of corporate environmental policy. Organizacija, v. 44, n. 6, p. 179-184, 2011. http://dx.doi.org/10.2478/ v10051-011-0019-4 
O'ROURKE, A. The message and methods of ethical investment. Journal of Cleaner Production, v. 11, n. 6, p. 683-693, 2003. http://dx.doi.org/10.1016/ S0959-6526(02)00105-1

ORTAS, E.; BURRITT, R. L.; MONEVA, J. M. Socially Responsible Investment and cleaner production in the Asia Pacific: does it pay to be good? Journal of Cleaner Production, v. 52, n. 1, p. 272-280, 2013. http://dx.doi. org/10.1016/j.jclepro.2013.02.024

PERRINGS, L. Reserved rationality and the precautionary principle: technological change, time and uncertainty in environmental decision making. In: CONSTANZA, R. Ecological economics: the science and management of sustainability. New York: Columbia University Press, 1991.

PETER, K.; HENRIËTTE, P. What does behavioral economics mean for policy? Challenges to savings and health policies in the Netherlands. De Economist, v. 158, n. 2, p. 101-122, 2010. http://dx.doi.org/10.1007/ s10645-010-9141-6

PICKETT-BAKER, J.; OZAKI, R. Pro-environmental products: marketing influence on consumer purchase. Journal of Consumer Marketing, v. 25, n. 5, p. 281-293, 2008.

POLÍTICA Nacional de Resíduos Sólidos. Subemenda Substitutiva Global de Plenário ao Projeto de Lei n ${ }^{\circ} 203$, de 1991, e seus apensos. Revista Sustentabilidade, 2010. Disponível em: <http://www.revistasustentabilidade. com.br/reciclagem/reciclagem/documentosinteressante/ relatorio-final-da-politica-de-residuos>. Acesso em: 9 out. 2010.

QU, D.; QU, J. Research on the priority of environmental tort obligation in bankrupt enterprises under the background of low carbon economy. Journal of Sustainable Development, v. 4, n. 2, p. 150-153, 2011. http://dx.doi. org/10.5539/jsd.v4n2p150

RADU, M. Corporate governance, internal audit and environmental audit: the performance tools in romanian companies. Accounting and Management Information Systems, v. 11, n. 1, p. 112-130, 2012.

REA, L. M.; PARKER, R. A. Designing and conducting survey research: a comprehensive guide. 2. ed. New York: John Wiley \& Sons, 1997. p. 304.

RICHIE, L.; OPPENHEIMER, J. D.; CLARK, S. G. Social process in grizzly bear management: lessons for collaborative governance and natural resource policy. . Policy Sciences, v. 45, n. 3, p. 265-291, 2012. http:// dx.doi.org/10.1007/s11077-012-9160-z

RIVELLI, E. A. Evolução da legislação ambiental no Brasil: políticas de meio ambiente, educação ambiental e desenvolvimento urbano. In: PHILLIP JUNIOR, A.; PELICIONI, M. C. F. Educação ambiental e sustentabilidade. Barueri: Malone, 2005. p. 285-302.

RIVERO, O. O mito do desenvolvimento: os países invisíveis no século XXI. Petrópolis: Vozes, 2002. p. 230.

RUMPALA, Y. "Sustainable consumption" as a new phase in a governmentalization of consumption. Theory and Society, v. 40, n. 6, p. 669-699, 2011. http://dx.doi. org/10.1007/s11186-011-9153-5

SAUERBRONN, F. F.; SAUERBRONN, J. F. R. Estratégias de responsabilidade social e esfera pública: um debate sobre stakeholders e dimensões sociopolíticas de ações empresariais. Revista de Administração Pública, v. 45, n. 2, p. 435-58, 2011. http://dx.doi.org/10.1590/ S0034-76122011000200007

SCANDIZZO, P. L.; KNUDSEN, O. K. Risk management and regulation compliance with tradable permits under dynamic uncertainty. European Journal of Law and Economics, v. 33, n. 1, p. 127-157, 2012. http://dx.doi. org/10.1007/s 10657-010-9140-8

SEIFFERT, M. E. B. Gestão ambiental: instrumentos, esferas e ação e educação ambiental. 1 ed. São Paulo: Atlas, 2010. p. 390.

SERVIÇO NACIONAL DE APRENDIZAGEM INDUSTRIAL - SENAI. Implementação de Programas de Produção mais Limpa. Porto Alegre: Centro Nacional de Tecnologias Limpas: SENAI-RS: UNIDO: INEP, 2003.

SETHI, S. P. Standards for corporate conduct in the international arena: challenges and opportunities for multinational corporations. Business and Society Review, v. 107, n. 1, p. 20-40, 2002. http://dx.doi. org/10.1111/0045-3609.00125

SHANGHAI Economic Commission. Guidance to Manufacturing Industry Development: GMID. 2009. Disponível em: <http://www.shec.gov.cn>.

SIMÃO, A. G. et al. Indicadores, políticas públicas e a sustentabilidade. In: SILVA, C. L.; SOUZA-LIMA, J. E. Políticas públicas e indicadores para o desenvolvimento sustentável. São Paulo: Saraiva, 2010. p. 35-54.

SINGH, A. Engineering mixes with politics. Construction Innovation, v. 12, n. 2, p. 128-132, 2012. http://dx.doi. org/10.1108/14714171211215976

STANISKIS, J.; ARBACIAUSKAS, V.; VARZINSKAS, V. Sustainable consumption and production as a system: experience in Lithuania. Clean Technologies and Environmental Policy, v. 14, n. 6, p. 1095-1105, 2012. http://dx.doi.org/10.1007/s10098-012-0509-y

STEURER, R. The role of governments in corporate social responsibility: characterising public policies on CSR in Europe. Policy Sciences, v. 43, n. 1, p. 49-72, 2010. http://dx.doi.org/10.1007/s11077-009-9084-4

TENCATI, A.; ZSOLNAI, L. Collaborative enterprise and sustainability: the case of slow food. Jounal Business Ethics, v. 110, n. 3, p. 345-354, 2012. http://dx.doi. org/10.1007/s10551-011-1178-1

TRIPATHY, D. P. Environmental auditing for sustainable development of indian industries. Asian Journal of Water, Environment and Pollution, v. 8, n. 4, p. . 9-20, 2011.

UNITED NATIONS ENVIRONMENT PROGRAME - UNEP. Understanding resource efficcient and cleaner production. Paris: UNEP, 1989. Disponível em: <http://www.unep.fr/scp/cp/ understanding/concept.htm>. Acesso em: 20 fev. 2010.

VACCARO, A.; ECHEVERRI, D. P. Corporate transparency and green management. Journal of Business Ethics, v. 95, n. 3, p. 487-506, 2010. http://dx.doi.org/10.1007/ s10551-010-0435-z

VEIGA, J. E. Desenvolvimento sustentável: o desafio do século XXI. Rio de Janeiro: Garamond, 2005. p. 220. 
VON SCHOMBERG, R. The precautionary principle: its use within hard and soft law. European Journal of Risk Regulation, v. 3, n. 2,ıp. 147-156, 2012.

WANGLER, L. U. The political economy of the green technology sector: a study about institutions, diffusion and efficiency. European Journal of Law and Economics, v. 33, n. 1, p. 51-81, 2012. http://dx.doi.org/10.1007/ s10657-010-9149-z

YATES, A. J. On a fundamental advantage of permits over taxes for the control of pollution. Environmental \& Resource Economics, v. 51, n. 4, p. 583-598, 2012. http://dx.doi.org/10.1007/s10640-011-9513-7

YARIME, M. et al. Establishing sustainability science in higher education institutions: towards an integration of academic development, institutionalization, and stakeholder collaborations. Sustainability Science, v. 7, n. 1, p. 101-113, 2012. Supplement.

YU, J. Biorefinery of sweet sorghum stem. Biotechnology Advances, v. 30, n. 4, p. 811-816, 2012. PMid:22306167. http://dx.doi.org/10.1016/j.biotechadv.2012.01.014

ZAHARIA, C.; ZAHARIA, I. The dyanamics of ecologic-economic systems and the social value of the environmental. Economics, Management, and Financial Markets, v. 7, n. 1, p. 114-119, 2012.

ZAMAGNI, S. The lesson and warning of a crisis foretold: a political economy approach. Internacional Review Economics, v. 56, n. 3, p. 315-334, 2009. http://dx.doi. org/10.1007/s12232-009-0080-y

ZÁRATE-MARCO, A.; VALLÉS-GIMÉNEZ, J. The cost of regulation in a decentralized context: the case of the Spanish regions. European Journal of Law and Economics, v. 33, n. 1, p. 185-203, 2012. http://dx.doi. org/10.1007/s10657-010-9154-2

ZHANG, B. et al. Why do firms engage in environmental management? An empirical study in China. Journal of Cleaner Production, v. 16, n. 10, p. 1036-1045, 2008. http://dx.doi.org/10.1016/j.jclepro.2007.06.016

ZENG, S. X. et al. Towards corporate environmental information disclosure: an empirical study in China. Journal of Cleaner Production, v. 18, n. 12, p. 1142-1148, 2010. http://dx.doi.org/10.1016/j. jclepro.2010.04.005 